\title{
Ceramic Coated Piston Rods for Civil Works
}

Robert A. Weber and Raymond Zatorski

The U.S. Army Corps of Engineers uses many hydraulic pistons on its Civil Works structures. Recent failures of ceramic coated piston rods in the Jacksonville District indicate that specifications for these rods need to be updated and enhanced.

This report discusses results of tests performed on carbon steel rods with varying bond coats applied with one of several methods. Topcoats were also varied, and sealers were used only on some of the specimens. Testing was to determine hardness and corrosion/impact resistance.

Conclusions drawn in this study will be used to recommend modifications to Corps of Engineers Guide Specification 15010. 


\section{Foreword}

This study was conducted for Headquarters, U.S. Army Corps of Engineers under the Civil Works General Investigation funds work unit "Ceramic Coated Piston Rods, R\&D, Develop Specification"; 315 - Electrical/Mechanical Program, Work Unit 32868. The technical monitor was Dan Casapulla (CECW-EE).

The work was performed by the Materials and Structures Branch (CF-M), of the Facilities Division (CF), U.S. Army Construction Engineering Research Laboratory (CERL). The principal investigator for this project was Robert A. Weber. Raymond Zatorski of Zatorski Coatings Company is a consultant for CERL. Dr. Ilker Adiguzel is Chief, CF-M, and Michael Golish is Division Chief, CF. The CERL technical editor was Linda L. Wheatley, Information Technology Laboratory.

Dr. Michael J . O'Connor is the Director of CERL. 


\section{Contents}

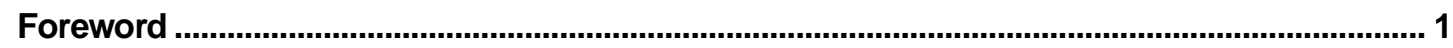

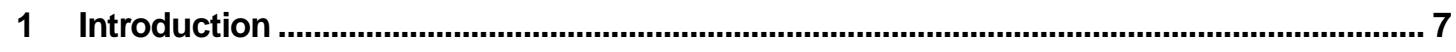

Background

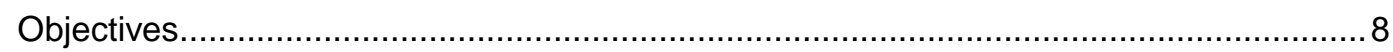

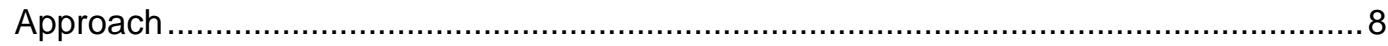

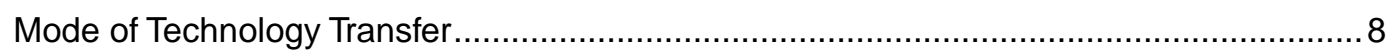

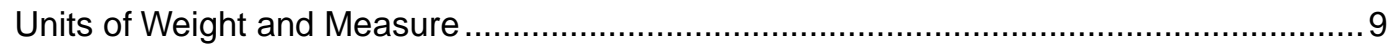

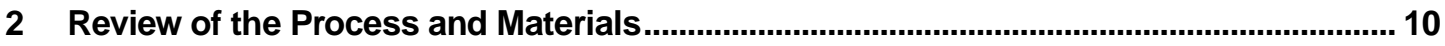

Discussions With Corps of Engineers Cylinder Users ................................................. 10

Discussions With Thermal Spray Industry Participants............................................... 10

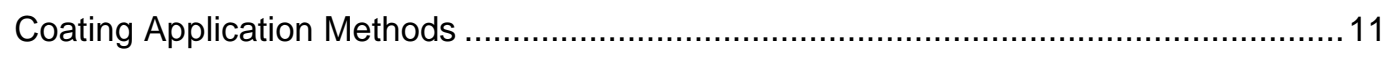

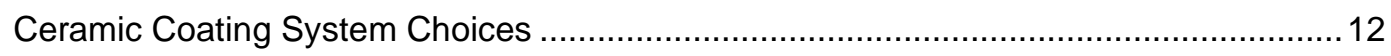

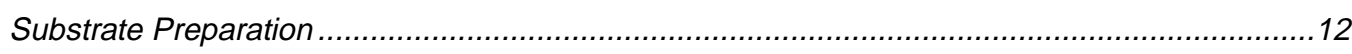

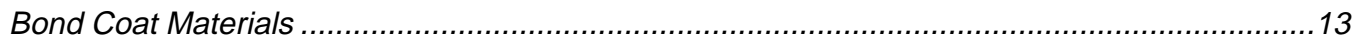

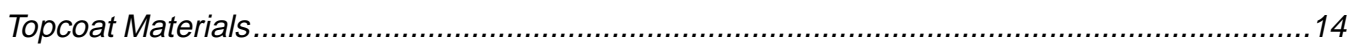

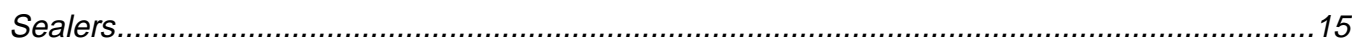

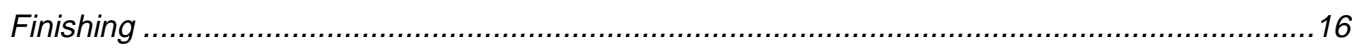

3 Failure Analysis of the Piston Rods at the Jacksonville District .................................... 17

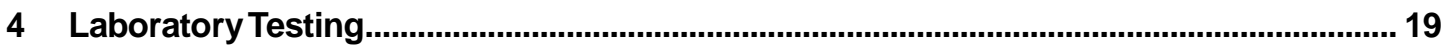

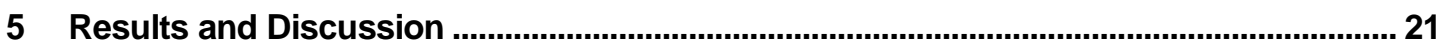

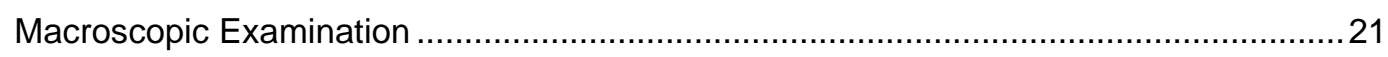

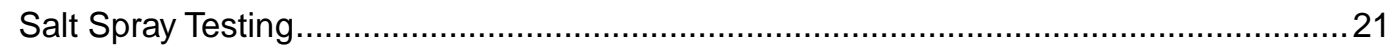

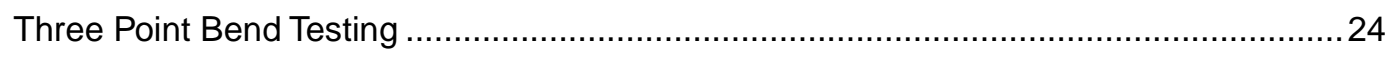

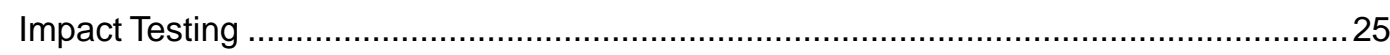

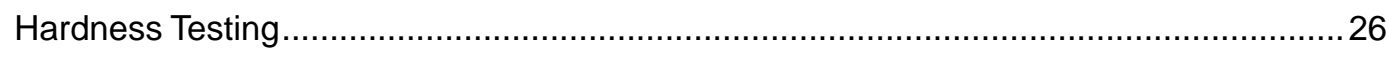

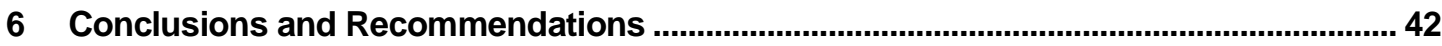

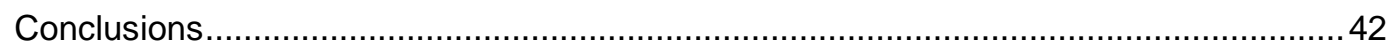

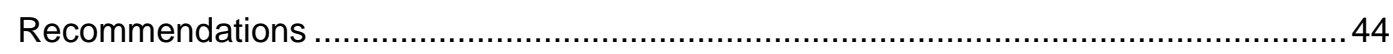




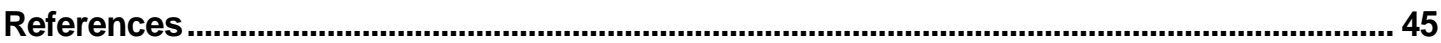
Distribution 


\section{List of Figures and Tables}

\section{Figures}

1 Cross section of alumina-13\% titania coating with nickel-chrome interlayer and no seal coat (Specimen 1).

2 Cross section of alumina-13\% titania coating with nickel-chrome interlayer and seal coat (Specimen 2).

3 Cross section of alumina-40\% titania coating with nickel-chrome interlayer and no seal coat (Specimen 3).

4 Cross section of alumina- $40 \%$ titania coating with nickel-chrome interlayer and seal coat (Specimen 4).

5 Cross section of alumina-13\% titania coating with nickel-chrome interlayer and no seal coat (Specimen 5).

6 Cross section of alumina-13\% titania coating with nickel-chrome interlayer and seal coat (Specimen 6)

7 Cross section of chromia coating with no interlayer and no seal coat (Specimen 7).

8 Cross section of chromia coating with no interlayer and no seal coat (Specimen 8).

9 Cross section of chromia coating with nickel-chrome interlayer and seal coat (Specimen 9).

10 Cross section of chromia coating with nickel-aluminum interlayer and seal coat (Specimen 10).

11 Cross section of chromia coating with nickel-chrome interlayer and no seal coat (Specimen 11).

12 Cross section of alumina-13\% titania coating with nickel-aluminum HVOC interlayer and no seal coat (Specimen 12).

13 Cross section of alumina-13\% titania with nickel-aluminum two-wire arc interlayer and no seal coat (Specimen 13).

14 Cross section of chromia-5\% silica-3\% titania coating with nickel-chrome interlayer and no seal coat (Specimen 14).

15 Cross section of alumina-13\% titania coating with 316 stainless steel interlayer and no seal coat (Specimen 15).

16 Cross section of chromia coating with 400 series stainless steel interlayer and no seal coat (Specimen 16)

17 Cross section of alumina- $40 \%$ titania coating with molybdenum interlayer and no seal coat (Specimen 17). 
18 Cross section of titania coating with nickel-chrome interlayer and seal coat (Specimen 18).

19 Cross section of alumina-3\% titania coating with nickel-chrome interlayer and no seal coat (Specimen 19)

20 Cross section of alumina-13\% titania coating with aluminum bronze interlayer

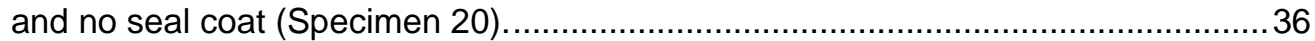

21 Cross section of the Rex Roth proprietary coating sample (Specimen 21). .............37

22 Specimen \#1 showing the results of the salt spray test. .........................................37

23 Specimen \#9 showing the results of the salt spray test; the last frame shows the cracks outlined in white.

24 Specimen \#7 bend test sample showing compression side (top) and tension side (bottom).

25 Specimen \#17 bend test sample showing compression side (top) and tension side (bottom)

26 Impact specimen \#16 showing results of impact energies of 5, 10, and 15 in.$\mathrm{lb}$, starting from the left.

27 Impact specimen \#15 showing results of impact energies of 5, 10, and 15 in.$\mathrm{lb}$, starting from the left.

\section{Tables}

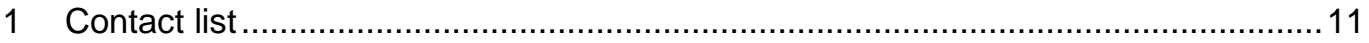

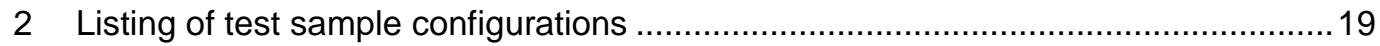

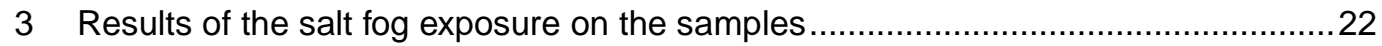

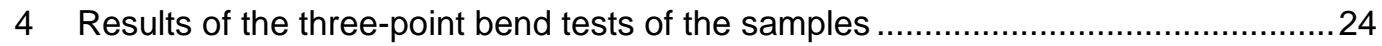

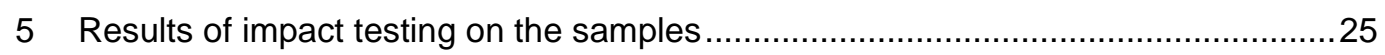

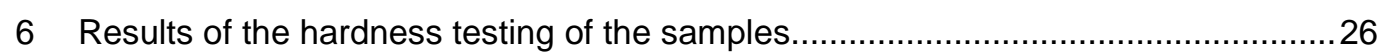




\section{Introduction}

\section{Background}

The Corps of Engineers uses many hydraulic pistons on Civil Works structures. Applications include wicket gate operations at hydro-electric plants, bulkhead gate operation, and tainter and miter gate operations. These include ceramic coated piston rods as well as the more conventional chromium coated pistons. The ceramic coated pistons provide improved performance, durability, and corrosion and abrasion resistance. Many manufacturers provide ceramic coated piston rods, but research was needed to determine the characteristics necessary for long-term performance in Civil Works projects. Recent failures in the J acksonville District after 2 years of service show that the specifications for ceramic coated piston rods need to be updated and enhanced. The results of this research will be used to develop specifications for piston rod performance.

The use of thermally sprayed ceramic coatings on pistons for fluid contact has been in commercial use since the 1950's. The majority of these coated pistons are for petroleum and chemical applications. The ceramic coatings are used in areas where increased hardness or increased corrosion resistance of the surface is needed. The ceramic coating has improved resistance to pitting corrosion compared to metallic coatings. In the vast majority of ceramic coatings, a metallic bond coat is used to prevent corrosion of the substrate, provide increased adhesion, and increase the allowable mechanical deflection of the coated component. The mechanical properties of a properly chosen metallic bond coat form a transition between the mechanical properties of the topcoat and the substrate. The use of ceramic coated piston rods is controlled by Corps of Engineers Guide Specification (CEGS) 15010, "Hydraulic Power Systems for Civil Works Structures." In sections 2.1.3.4, 2.1.4, and 2.1.5.1, the specification calls for the ceramic coating to be 200 micrometers ( $\mu \mathrm{m} ; 0.008 \mathrm{in}$.) minimum thickness, a surface finish of 0.30 to $0.35 \mu \mathrm{m}$ (12 to 14 micro-in.) rms, a surface hardness of $67 \mathrm{Rc}$ minimum, impact resistance of 7 to $15 \mathrm{~N}-\mathrm{m}$ (5 to $17 \mathrm{lb}$-ft), modulus of elasticity of 360 to $450 \mathrm{gPa}$ ( $52 \times 106$ to $60 \times 106 \mathrm{psi}$ ), linear expansion coefficient of $7.2 \times 10$ $6 /{ }^{\circ} \mathrm{C}\left(4.0 \times 10-6 /{ }^{\circ} \mathrm{F}\right)$ and capable of withstanding a fracture force of $280 \mathrm{mPa}$ (41 ksi) minimum. 
Ceramic coatings on steel or iron substrates are also used extensively in the printing and paper/pulp industries. In several of these applications, corrosion of the steel substrate is not an issue. In some cases, the coating will perform satisfactorily without a metallic bond coat where the mechanical deflection and thermal coefficient of expansion issues can be addressed. Discussions with industry personnel indicate that lack of a bond coat is not good practice and should be avoided. One of the thermal spray applicators, Plasma Technology, Inc., as a matter of policy will not supply the ceramic coatings without a bond coat, even if the customer's specification does not require a bond coat.

\section{Objectives}

The objective of this work was to evaluate the characteristics of ceramic coated piston rods necessary for long-term performance on Civil Works facilities in order to develop improved specifications for these coatings. Properties of the ceramic coated pistons to be investigated include: modulus of elasticity, hardness, coefficient of thermal expansion, fracture strength, impact resistance, layer thickness, surface hardness, and surface finish.

\section{Approach}

The approach to this work included a literature survey of ceramic coating systems used for piston rods, interviews of Corps personnel to identify potential problems with current specifications, and evaluation of materials properties and processing techniques critical to long-term performance on Civil Works facilities. Corrosion resistance of the ceramic coating system was evaluated in a salt spray test as outlined in American Society for Testing and Materials (ASTM) B117. Resistance to micro-cracking was determined by bend tests, and hardness testing was conducted on all materials. The results of these tests will be used to devel op guidance for the use of ceramic coated piston rods.

\section{Mode of Technology Transfer}

The technol ogy developed in this research will be used to form recommendations to modify the Corps of Engineers Guide Specifications. 


\section{Units of Weight and Measure}

U.S. standard units of measure are used in this report. A table of conversion factors for Standard International (SI) units is provided below.

\begin{tabular}{|c|c|c|}
\hline \multicolumn{3}{|c|}{ SI conversion factors } \\
\hline 1 in. & $=$ & $2.54 \mathrm{~cm}$ \\
\hline 1 in.-lb & $=$ & $0.1129848 \mathrm{~N} \cdot \mathrm{m}$ \\
\hline $1 \mathrm{ft}$ & $=$ & $0.305 \mathrm{~m}$ \\
\hline $1 \mathrm{lb}$ & $=$ & $0.453 \mathrm{~kg}$ \\
\hline $1 \mathrm{lb}-\mathrm{ft}$ & $=$ & $1.355818 \mathrm{~N} \cdot \mathrm{m}$ \\
\hline 1 psi & $=$ & $6.89 \mathrm{kPa}$ \\
\hline${ }^{\circ} \mathrm{F}$ & $=$ & $\left({ }^{\circ} \mathrm{C} \times 1.8\right)+32$ \\
\hline
\end{tabular}




\section{Review of the Process and Materials}

\section{Discussions With Corps of Engineers Cylinder Users}

Two groups of users were interviewed regarding their experience with ceramic coated piston rods. The first group was at the Corps Hydroelectric Design Center in Portland, OR. The second group was at the J acksonville District, J acksonville, FL. Three waterway structures including the W.P. Franklin, More Haven, and S-12 locks were viewed in South Florida.

\section{Discussions With Thermal Spray Industry Participants}

Ray Zatorski (Zatorski Coating Company, Inc.) discussed the coating application processes, methodology, and the philosophy of coating systems with a cross section of coated piston rod users, thermal spray coating suppliers, and thermal spray coating equipment and material suppliers. Table 1 lists these personnel and their affiliations. In addition to those listed in Table 1, other personnel were contacted by telephone to discuss ceramic coatings for pistons.

In the interviews with personnel involved in the thermal spray industry, coatings for pistons in general were discussed first and then thermally sprayed metallic or ceramic coatings were discussed in detail. Based on experience, the majority of the participants favored the ceramic metal-oxide coatings over other choices such as an all metallic system or a carbide system. The most recommended coating system was a bond coat of nickel chrome, a topcoat of alumina-13\% titania or chromia with a penetrating sealer. The choices of sealers varied among epoxies, polyamides, urethanes, and phenolics. The potential coating choices appear below.

In specifying a ceramic coating for piston application, the corrosion performance in the environment was cited as the most important factor. Wear and compatibility to the other mating components were enumerated next. Bond strength and mechanical properties were specified last. 
Table 1. Contact list.

\begin{tabular}{|l|l|}
\hline Person Contacted & Affiliation \\
\hline Jean Mozolic & H. C. Starck \\
Product Manager for & 45 Industrial Place \\
Surface Technology Products & Newton, MA 02161 \\
\hline Parveen Gupta & The Rexroth Corporation \\
Marketing Manager & Industrial Hydraulics Division \\
Hydraulics for Civil Engineering & 2315 City Line Road \\
& Bethlehem, PA 18017 \\
\hline Rick Bajan & Plasma Technology, Inc. \\
Sales Engineer & 70 Rye Street \\
& South Windsor, CT 06074 \\
\hline Richard Kaufold & Alcoa Technical Center \\
Staff Engineer & 100 Technical Drive \\
Product and Process Technology Division & Alcoa Center, PA 15069 \\
\hline John Rienecker & Metco \\
Sales Engineer & 1101 Prospect Ave. \\
& Westbury, NY 11590 \\
\hline
\end{tabular}

\section{Coating Application Methods}

The coating application method directly affects the coating structure and, consequently, the coating's properties. The most popular methods of coating deposition for these types of applications are arc-plasma spray for all layers, two-wire arc for the metallic bond coats, and high velocity oxygen fuel (HVOF) systems for the metallic layers. Powder combustion guns are low velocity fuel oxygen coating systems that usually do not produce a coating dense enough for this application.

The majority of the installed base of two-wire arc systems produce coatings that are inferior to arc-plasma coatings. Some of the newer systems with developed parameters can produce coatings that are near or the equivalent of arc-plasma coatings.

The newer HVOF systems can be used to apply the ceramic systems; most of the present units can only apply metals. Praxair (formally Union Carbide Coating Service) also uses a D-gun, which is a decades-old type of intermittent HVOF system. This system produces industry standard coatings. 


\section{Ceramic Coating System Choices}

The potential coating systems are listed according to the steps and coating layers. Each step or layer is further categorized into Recommended, Acceptable, and N ot Acceptable. General comments precede the categories.

\section{Substrate Preparation}

Preparation of the substrate surface is imperative for good bonding of the coating system. The substrate surface must be free of all organic material, scale, and debris. Organic material includes oil, grease, and even oil from fingerprints. Scale includes gross mill scale or rust, and loosely adhered metallic pieces such as chips. Debris includes imbedded oxides, packing material such as plastics, or concrete dust. After the surface is dean, the part is roughened by a method such as grit blasting in preparation for coating application. The grit-blasted surface must have the same roughness across the part.

\section{Surface Preparation, Recommended}

Clean the surface to remove gross scale and debris and to remove the organics, sometimes called "degreasing." Grit blast the surface with new, clean, sized grit at pressures to provide an even, surface roughness. Surface profiles of Ra 350 micro-inches to Ra 500 micro-inches have produced good surfaces for bonding. Apply bond coat within 4 hours of surface preparation.

\section{Surface Preparation, Acceptable}

Follow the "Recommended" steps by covering the part with a tight fitting plastic wrap for coating at a later time (up to 3 or 4 days later). Alternatively, the surface can be cleaned as in "Recommended" with the addition of grinding a surface roughness into the substrate.

\section{Surface Preparation, Not Acceptable}

Not cleaning the organics prior to grit blasting is unacceptable. Grit blasting can entrap organics or debris into the substrate. Not roughening the surface is also unacceptable. The "self-bonding" of the bond coat materials is inadequate in this application. This can be easily quantified using a tensile bond strength test. 


\section{Bond Coat Materials}

For bond coats, the metal alloys must be pre-alloyed. Composite materials such as agglomerated nickel-aluminum are specifically not recommended. While alloying does occur in the plasma flame, some free components of the composite material are always present in the coating. The more electrolytically active free component will corrode preferentially to cathodically protect the deposited coating. For example, the corrosion resistance of composite nickel-aluminum is less than one-fourth of the corrosion resistance of pre-alloyed nickel-aluminum alloy on steel as observed in the ASTM B-117 salt-spray test. Care must be taken in selecting the metallic powders of any alloy. The vendors may supply both the agglomerated and pre-alloyed versions of the same material. For example, Metco supplies agglomerated nickel-aluminum powder as Metco 450. The same constituents in pre-alloyed form are supplied as Metco 480 powder.

Porosity should be low as measured by optical methods on polished specimens. For example, the porosity of the bond coat should be less than 2 percent for nickel-chrome.

\section{Bond Coat Materials, Recommended}

Nickel-chrome alloy, applied by plasma or high-velocity oxygen-fuel (HVOF), is corrosion resistant. The coating can have porosity problems when applied by two-wire arc spray, reducing corrosion resistance. This problem can be addressed by proper choice of equipment and spray parameters, which will require additional effort.

Nickel-aluminum alloy, applied by plasma, HVOF, or two-wire arc, is corrosion resistant.

Molybdenum, applied by plasma, HVOF, or two-wire arc, is corrosion resistant.

\section{Bond Coat Materials, Acceptable}

Type 420 or 431 stainless steel, applied by plasma or HVOF, is corrosion resistant. These coatings applied by two-wire arc coating can have porosity problems, reducing corrosion resistance.

Type 316 stainless steel, applied by plasma or HVOF, is corrosion resistant. These coatings applied by two-wire arc coating can have porosity problems, reducing corrosion resistance. 
Aluminum bronze (90 percent copper, 9 percent aluminum, and 1 percent iron) applied by plasma, HVOF, or two-wire arc, is corrosion resistant, but can be too soft for the topcoat. In a corrosive environment, this material can accelerate corrosion at the bond coat to substrate interface due to the differences in electrochemical potential. This problem can cause breaches in the coating such as dings or small cracks where water with high conductivity can enter.

\section{Bond Coat Materials, Not Acceptable}

Any composite metal such as composite nickel-aluminum is unacceptable because the free metal constituents accelerate corrosion.

Any material applied by combustion powder spray can have large amounts of porosity. Any metals with insufficient hardness to support loads imposed on the ceramic are also unacceptable.

\section{Topcoat Materials}

Several topcoat materials are commonly used for these types of applications. Preference for these materials is due to a combination of hardness, ability to mate with the other components in the cylinder, ability to be finished, and economy of application. The porosity should be low as measured by optical methods on polished specimens. For example, the porosity should be less than 4 percent for alumina-titania topcoats and 2 percent for nickel-chrome.

\section{Topcoat Materials, Recommended}

Alumina-13\% titania or alumina-10\% titania, applied by plasma or HVOF systems, provide dense coatings that yield an excellent surface finish.

Alumina- $40 \%$ titania, applied by plasma or HVOF systems, provides dense coatings with excellent surface finish, although they are softer than alumina$13 \%$ titania.

Chromia, applied by plasma or HVOF systems, provides a dense coating with excellent surface finish.

Chromia-5\% silica-3\% titania, applied by plasma or HVOF systems, provides a dense, extremely hard coating that yields an excellent surface finish. 


\section{Topcoat Materials, Satisfactory}

Alumina-3\% titania, applied by plasma or HVOF systems, provides a dense coating that can be difficult to finish. The application can be technique dependent. Cracking can occur during grinding.

Alumina, applied by plasma or HVOF systems, provides a dense coating. It can be difficult to finish, can be technique dependent to apply, and cracking can occur during grinding.

Titania, applied by plasma or HVOF systems, provides a dense coating with excellent surface finish. The coating can be too soft for the hydraulic cylinder type of service.

\section{Topcoat Materials, Not Recommended}

Partially stabilized zirconia (e.g., yttria-zirconia or calcia-zirconia), are usually too soft for this type of service.

Any ceramic applied by powder combustion spray because of increased porosity and greatly decreased hardness is not recommended.

\section{Sealers}

The function of the sealer is to block passage through the inherent porosity of thermally sprayed coatings to the substrate. However, sealers are not a fix for a coating that has excessive porosity. These coatings should be stripped and reapplied. As mentioned earlier, the porosity of the bond coat should be less than 2 percent for nickel-chrome and less than 4 percent for alumina-titania top coats. A large number of sealer choices are available that can be applied by a number of methods. The characteristics of a good sealer are the ability to penetrate the inherent porosity of the coatings, stability in the service environment, and the ability to block the fluids from passing through the porosity of the coating.

\section{Sealers, Recommended}

Low viscosity sealants are recommended if they will penetrate (i.e., have good wetability), are either curing or adhesive, are moisture resistant, and are compatible with hydraulic fluid. Materials such as phenolics, low viscosity epoxies (i.e., Lock-Tite 190), urethanes, silicones, and polyamides fall into this category. 


\section{Sealers, Satisfactory}

Melt-in waxes are satisfactory, but application can be technique dependent and many can be dissolved in hydraulic fluid.

\section{Sealers, Not Recommended}

Surface barrier type sealers that are characterized by high viscosity are not recommended. Sealers that can be displaced by moisture such as oil-based penetrants are not recommended. Any hygroscopic sealers (usually polymer based) are not recommended.

\section{Finishing}

The coatings should be finished by grinding. The parameters need to be adjusted to minimize damage to the coating structure, which can be verified by microscopically inspecting polished sections of the ground coating from test parts. Damage is usually in the form of parallel cracks at the top of the coating. 


\section{Failure Analysis of the Piston Rods at the Jacksonville District}

Many of the ceramic coated pistons observed in south Florida had cracked and spalled coatings. The J acksonville District asked CERL to perform an analysis of the failures. The analysis consisted of field observations and laboratory testing of samples taken from the failed piston coatings. In the laboratory, each specimen was visually inspected and underwent metallurgical analysis and $\mathrm{X}$ ray diffraction. The ceramic coated piston rods of three structures were observed to determine field conditions and the current state of the coatings. Inspectors took specimens from the failed coatings at two dam structures, the S-12 and the W.P. Franklin. The specimens were visually inspected for surface contour and general appearance. Some specimens were mounted, polished, and observed under high magnification to determine the microstructure of their coatings. Some other specimens were analyzed for chemical composition by X-ray diffraction. Based on observations in the field and the laboratory, the following conclusions can be made about the failure of the ceramic coated piston rods on the W.P. Franklin and S-12 structures:

1. The piston rods show varying degrees of coating spallation.

2. The ceramic coatings are being forced off the piston rods by the expansion of corrosion products at the interface of the coating and the substrate.

3. Metallurgical analysis of the coating chips did not reveal the presence of an interlayer to improve bonding and slow corrosion.

4. Metallurgical analysis also showed the coating to be of varying density and to have laminar and transverse cracking.

5. Water and hydraulic fluid were present in the pores of the ceramic coating. 
Based on the evaluation of the failed ceramic coatings, it was recommended that the piston rod be repaired where the spalling is less than $1 \mathrm{in.}(25.4 \mathrm{~mm})$. The remainder of the spalled piston rods will have to be replaced. The piston rods that were not affected should be monitored closely and any indication of problems should be dealt with immediately. Consideration should be given to putting a seal coat on the unaffected piston rods if they do not al ready have one. 


\section{Laboratory Testing}

Based on discussions with the users, industry suppliers, and a consultant, Table 2 was developed as a matrix for the testing of various combinations of bond coat, ceramic, and seal coat. These combinations of materials were applied to test specimens of $1 / 2$-in.-diameter carbon steel rod. All surface preparation was performed by sand blasting the test samples to a surface roughness of 350 to 500 micro-inches, except for sample 7, which had a surface roughness of 200 to 300 micro-inches. During this work, the Rexroth Corporation was contacted for permission to test a sample of their proprietary coatings in with the generic systems tested in this research. They provided samples of their coatings on 2-in.-diameter rod stock.

Table 2. Listing of test sample configurations.

\begin{tabular}{|c|c|c|c|}
\hline Spec. No. & Bond Coat & Topcoat & Sealer \\
\hline 1 & $\mathrm{Ni}-\mathrm{Cr}$, Plasma & Alumina-13\% Titania & None \\
\hline 2 & Ni-Cr, Plasma & Alumina-13\% Titania & Yes \\
\hline 3 & $\mathrm{Ni}-\mathrm{Cr}$, Plasma & Alumina-40\% Titania & None \\
\hline 4 & Ni-Cr, Plasma & Alumina-40\% Titania & Yes \\
\hline 5 & Ni-Cr, Plasma & Alumina-13\% Titania & None \\
\hline 6 & $\mathrm{Ni}-\mathrm{Cr}$, Plasma & Alumina-13\% Titania & Yes \\
\hline $7^{*}$ & None & Chromia & None \\
\hline 8 & None & Chromia & None \\
\hline 9 & $\mathrm{Ni}-\mathrm{Cr}$, Plasma & Chromia & Yes \\
\hline 10 & Ni-Al, Plasma & Chromia & Yes \\
\hline 11 & Ni-Cr, Plasma & Chromia & None \\
\hline 12 & $\mathrm{Ni}-\mathrm{Al}, \mathrm{HVOF}$ & Alumina-13\% Titania & None \\
\hline 13 & $\mathrm{Ni}$-Al, 2-wire arc & Alumina-13\% Titania & None \\
\hline 14 & Ni-Cr, Plasma & Chromia-5\% Silica-3\% Titania & None \\
\hline 15 & 316 SS, plasma & Alumina-13\% Titania & None \\
\hline 16 & 400 series SS, plasma & Chromia & None \\
\hline 17 & Molybdenum, plasma & Alumina-40\% Titania & None \\
\hline 18 & Ni-Cr, Plasma & Titania & Yes \\
\hline 19 & $\mathrm{Ni}-\mathrm{Cr}$, Plasma & Alumina-3\% Titania & None \\
\hline 20 & Aluminum bronze, 2-wire arc & Alumina-13\% Titania & None \\
\hline 21 & Rexroth Proprietary & Coating & \\
\hline
\end{tabular}


Each sample coating system was subjected to corrosion and mechanical testing. Four rods of each coating combination were produced, one for each type of test: salt spray, three-point bend, impact, and hardness.

The salt spray testing was run according to ASTM B-117-90 "Standard Test Method of Salt Spray (Fog) Testing." The test was conducted for 2,000 hours in a salt-spray chamber. Every 500 hours the specimens were removed from the chamber, the condition of the specimens was noted, and a photograph of each specimen was taken as a permanent record of the test condition.

The mechanical tests for three-point bend, impact, and hardness were also run according to ASTM standards. Coating system sample rods were tested according to ASTM E-290-92 "Standard Test Method for Semi-Guided Bend Test for Ductility of Metallic Materials" (three-point bend), ASTM D-2794-93 "Standard Testing Method for Resistance of Organic Coatings to the Effects of Rapid Deformation (impact)," and ASTM E-18-93 "Standard Test Methods for Rockwell Hardness and Rockwell Superficial Hardness of Metallic Materials." 


\section{Results and Discussion}

\section{Macroscopic Examination}

Figures 1 through $21^{*}$ are macro photographs of each of the test samples. The specimens were cut perpendicular to the axis of the rod. The cross sections were polished using standard metallographic practices and photographed at 100x magnification. Each photograph shows the steel substrate on top, the bond coat, and the ceramic coating at the bottom. Specimens 7 and 8 do not have a bond coat. The bond coats on specimens $2,3,4,6,10,13$, and 19 contain porosity. The topcoats on all specimens contain pores. The spray process does not produce a 100 percent dense coating. The presence of porosity shows why a sealer is needed to help seal out the oils and water from the substrate. The pores can be connected and allow corrosives into the substrate, but a sealer and a corrosionresistant bond coat protect the substrate from corrosion.

\section{Salt Spray Testing}

Table 3 lists the observations from the salt fog test. Specimens 1, 5, 6, 12, 13, 15, and 19 are free from any corrosion of the substrate. Specimen 7 showed some dulling of the gloss and the remainder have varying degrees of cracking and spalling of the coating. Specimen 6 is the only one of the group that survived the salt spray test for 2,000 hours that had a seal coat. Specimens 1, 5, 6, and 19 had bond coats of nickel-chrome applied with plasma spray. Specimens 12 and 13 had nickel-aluminum bond coats applied by HVOF and arc spray, respectively. Specimen 15 had a 316 stainless steel bond coat applied with plasma spray. Specimen 7 had no bond coat and had a topcoat of Chromia. The substrate of the failed specimens had corroded under the ceramic coating. The corrosion started as a spot and grew until the corrosion products expanded sufficiently to cause the coating to crack in most cases. Figure 22 shows the stages of the test for sample 1. Figure 23 shows the stages of the test for sample 9 . These two figures

\footnotetext{
* Figures appear at the end of this chapter.
} 
are typical of the test specimens that passed and failed, respectively, from the salt spray test.

Table 3. Results of the salt fog exposure on the samples.

\begin{tabular}{|c|c|c|}
\hline Specimen & $\begin{array}{l}\text { Exposure } \\
\text { Time (hr) } \\
\end{array}$ & Observations \\
\hline \multirow[t]{4}{*}{1} & 500 & No blisters, cracks, or rust through. \\
\hline & 1000 & No blisters, cracks, or rust through. \\
\hline & 1500 & No blisters, cracks, or rust through. \\
\hline & 2000 & No blisters, cracks, or rust through. \\
\hline \multirow[t]{4}{*}{2} & 500 & No blisters, cracks, or rust through. \\
\hline & 1000 & Two rust spots forming at one site on specimen. \\
\hline & 1500 & No change. \\
\hline & 2000 & Two rust spots now well defined as rust through. \\
\hline \multirow[t]{4}{*}{3} & 500 & One rust spot at lower end of specimen. \\
\hline & 1000 & Original rust spot has enlarged and another started. \\
\hline & 1500 & No change. \\
\hline & 2000 & Cracks through coating range from 1 to $2-3 / 4$ in. in length. \\
\hline \multirow[t]{4}{*}{4} & 500 & Rust spots forming at top of specimen. \\
\hline & 1000 & One crack with rust through extending full length of specimen. \\
\hline & 1500 & Two additional cracks with rust through. \\
\hline & 2000 & $>10$ cracks through coating from $3 / 4$ to $3 \mathrm{in}$. long. \\
\hline \multirow[t]{4}{*}{5} & 500 & No blisters, cracks, or rust through. \\
\hline & 1000 & No blisters, cracks, or rust through. \\
\hline & 1500 & No blisters, cracks, or rust through. \\
\hline & 2000 & No blisters, cracks, or rust through. \\
\hline \multirow[t]{4}{*}{6} & 500 & No blisters, cracks, or rust through. \\
\hline & 1000 & No blisters, cracks, or rust through. \\
\hline & 1500 & No blisters, cracks, or rust through. \\
\hline & 2000 & No blisters, cracks, or rust through. \\
\hline \multirow[t]{4}{*}{7} & 500 & No blisters, cracks, or rust through. \\
\hline & 1000 & Some loss of gloss. \\
\hline & 1500 & No change. \\
\hline & 2000 & No change. \\
\hline \multirow[t]{4}{*}{8} & 500 & Rust spots are forming at two sites. \\
\hline & 1000 & Rust spots are more dense. \\
\hline & 1500 & No change. \\
\hline & 2000 & Rust spots, loss of gloss, but no cracks can be seen. \\
\hline \multirow[t]{4}{*}{9} & 500 & No blisters, cracks, or rust through. \\
\hline & 1000 & Rust through is beginning at several sites. \\
\hline & 1500 & Cracks are forming with rust through. \\
\hline & 2000 & Cracks through the coating from $1 / 2$ to 3 in. in length. \\
\hline \multirow[t]{4}{*}{10} & 500 & No blisters, cracks, or rust through. \\
\hline & 1000 & Some rust spots are forming. \\
\hline & 1500 & Some cracks are forming. \\
\hline & 2000 & Cracks have propagated through full length of specimen. \\
\hline \multirow[t]{3}{*}{11} & 500 & Two very small rust spots have developed. \\
\hline & 1000 & Rust spots are more numerous. \\
\hline & 1500 & Cracks are beginning to form. \\
\hline
\end{tabular}




\begin{tabular}{|c|c|c|}
\hline Specimen & $\begin{array}{l}\text { Exposure } \\
\text { Time (hr) }\end{array}$ & Observations \\
\hline & 2000 & Cracks have propagated through full length of specimen. \\
\hline \multirow[t]{4}{*}{12} & 500 & No blisters, cracks, or rust through. \\
\hline & 1000 & No blisters, cracks, or rust through. \\
\hline & 1500 & No blisters, cracks, or rust through. \\
\hline & 2000 & No blisters, cracks, or rust through. \\
\hline \multirow[t]{4}{*}{13} & 500 & No blisters, cracks, or rust through. \\
\hline & 1000 & No blisters, cracks, or rust through. \\
\hline & 1500 & No blisters, cracks, or rust through. \\
\hline & 2000 & No blisters, cracks, or rust through. \\
\hline \multirow[t]{4}{*}{14} & 500 & Considerable rust through at lower end. \\
\hline & 1000 & Rust through is more extensive and cracks are forming. \\
\hline & 1500 & Cracks with rust through extending full length of specimen. \\
\hline & 2000 & Multiple cracks through full length of specimen. \\
\hline \multirow[t]{4}{*}{15} & 500 & No blisters, cracks, or rust through. \\
\hline & 1000 & No blisters, cracks, or rust through. \\
\hline & 1500 & No blisters, cracks, or rust through. \\
\hline & 2000 & No blisters, cracks, or rust through. \\
\hline \multirow[t]{4}{*}{16} & 500 & No blisters, cracks, or rust through. \\
\hline & 1000 & Rust staining on coating surface, but no rust through. \\
\hline & 1500 & Rust staining on coating surface, but no rust through. \\
\hline & 2000 & Rust staining on coating surface, but no rust through. \\
\hline \multirow[t]{4}{*}{17} & 500 & Considerable rust through at lower end and one spot at top. \\
\hline & 1000 & Rusting is extensive. \\
\hline & 1500 & Rusting is extensive. \\
\hline & 2000 & Rusting is extensive with at least one crack through full length. \\
\hline \multirow[t]{4}{*}{18} & 500 & No blisters, cracks, or rust through. \\
\hline & 1000 & Rust spots beginning to form. \\
\hline & 1500 & Rust spots more extensive with cracks forming. \\
\hline & 2000 & Cracks have propagated through full length of specimen. \\
\hline \multirow[t]{4}{*}{19} & 500 & No blisters, cracks, or rust through. \\
\hline & 1000 & No blisters, cracks, or rust through. \\
\hline & 1500 & No blisters, cracks, or rust through. \\
\hline & 2000 & No blisters, cracks, or rust through. \\
\hline \multirow[t]{4}{*}{20} & 500 & No blisters, cracks, or rust through. \\
\hline & 1000 & Rust spots are beginning to form. \\
\hline & 1500 & Cracks are forming at rust spots. \\
\hline & 2000 & Cracks are longer. \\
\hline \multirow[t]{4}{*}{21} & 500 & No blisters, cracks, or rust through. \\
\hline & 1000 & No blisters, cracks, or rust through. \\
\hline & 1500 & Some rust spots forming. \\
\hline & 2000 & More rust spots but no cracks. \\
\hline
\end{tabular}




\section{Three Point Bend Testing}

Table 4 shows the results of the bend testing conducted on the specimens. As was expected, the coatings of most specimens could not withstand much axial bending before they cracked. The coatings for the most part have very low ductility compared to the carbon steel substrate. All specimens were subjected to a bending force of approximately 2,250 lb because the coating of specimen 1 began to crumble from the compression forces at the contact points. Specimens 7 and 16 showed the best results with no cracks appearing on the tension side. All the rest had some cracking on the tension side. The compression side had varying results from nothing at all to moderate spalling and cracking. Figure 24 shows specimen 7 with no cracks and an obvious bend. Figure 25 shows specimen 17, the worst case from the bend test. The Rexroth samples could not be tested in the three-point bend apparatus because they were sprayed on 2-in.-diameter steel substrate and would have exceeded the capacity of the test machine since the other coatings were on $1 / 2$-in.-diameter steel rods.

Table 4. Results of the three-point bend tests of the samples.

\begin{tabular}{|c|l|l|}
\hline $\begin{array}{c}\text { Specimen } \\
\text { No. }\end{array}$ & \multicolumn{2}{|c|}{ Observations of the Bend Specimens } \\
\hline & Tension Side & Compression Side \\
\hline 1 & 18 parallel cracks. & Spalled area. \\
\hline 2 & 24 parallel cracks, very small spalled area. & Nothing. \\
\hline 3 & 6 parallel cracks. & Compression cracks. \\
\hline 4 & 11 parallel cracks. & Very small spalled area. \\
\hline 5 & 20 parallel cracks, spalled area. & Spalled area. \\
\hline 6 & 19 parallel cracks. & Nothing. \\
\hline 7 & 4 parallel cracks. & Nothing. \\
\hline 8 & 8 parallel cracks. & Large spalled area. \\
\hline 9 & 10 parallel cracks, small spalled area. & Large spalled area. \\
\hline 10 & 10 parallel cracks, spalled area. & Nothing. \\
\hline 11 & 6 parallel cracks. & Large spalled area. \\
\hline 12 & 14 parallel cracks. & Compression cracks. \\
\hline 13 & 11 parallel cracks. & Large spalled area. \\
\hline 14 & 11 parallel cracks, small spalled area. & Spalled area. \\
\hline 15 & 18 parallel cracks. & Compression cracks. \\
\hline 16 & Nothing. & Nothing. \\
\hline 17 & 7 parallel cracks. & Large spalled area. \\
\hline 18 & 18 parallel cracks. & Spalled area. \\
\hline 19 & 12 parallel cracks. & Nothing. \\
\hline 20 & 12 parallel cracks. & Large spalled area. \\
\hline & & \\
\hline
\end{tabular}




\section{Impact Testing}

All of the specimens were subjected to three impacts of 5,10 , and $15 \mathrm{in}$.ll force. The results of the impacts were determined by visual inspection of the impact area. Table 5 shows the results of the impact tests. Specimens 1, 3, 7, 18, and 21 had minimal cracking as a result of the 5 in.-lb impact. Specimens 4, 12, 13, 15, and 21 had no spalling and only some cracking at the $15 \mathrm{in}$.-lb energy level. Overall, specimens 15 and 21 did the best in the varying impact loading. Figure 26 shows specimen 16, which was one of the worst cases with major spalling and cracking through all three impact areas. Figure 27 shows specimen 15 impact areas, which have no spalling and minimal cracking through all three impact areas.

Table 5. Results of impact testing on the samples.

\begin{tabular}{|c|c|c|c|}
\hline $\begin{array}{l}\text { Specimen } \\
\text { No. }\end{array}$ & & Impact Results & \\
\hline & 5 in-lb & 10 in-lb & 15 in-lb \\
\hline 1 & 1 radial crack & 8 radial cracks & 8 radial cracks and loose area \\
\hline 2 & 2 very small radial cracks & 6 small radial cracks & 9 radial cracks and loose area \\
\hline 3 & 1 small radial crack & 2 small radial cracks & 4 small radial cracks and loose area \\
\hline 4 & 2 small radial cracks & 4 radial cracks & 10 radial cracks \\
\hline 5 & 3 small radial cracks & 6 small radial cracks & 10 small radial cracks and loose area \\
\hline 6 & 8 small radial cracks & 6 small radial cracks & 9 small radial cracks and loose area \\
\hline 7 & $\begin{array}{l}1 \text { radial crack and me- } \\
\text { dium spall area }\end{array}$ & 6 radial cracks & $\begin{array}{l}3 \text { radial cracks and medium spall } \\
\text { area }\end{array}$ \\
\hline 8 & $\begin{array}{l}2 \text { radial cracks and small } \\
\text { spall area }\end{array}$ & 6 radial cracks & 8 radial cracks and small spall area \\
\hline 9 & $\begin{array}{l}4 \text { radial cracks and spall } \\
\text { area }\end{array}$ & 5 radial cracks and spall area & 8 radial cracks and loose area \\
\hline 10 & 4 small radial cracks & 7 radial cracks and 2 spall areas & $\begin{array}{l}6 \text { radial cracks, spall area and looses } \\
\text { area }\end{array}$ \\
\hline 11 & 2 small radial cracks & 7 radial cracks and 2 spall areas & 9 radial cracks and small spall area \\
\hline 12 & 6 small radial cracks & 8 radial cracks & 10 radial cracks \\
\hline 13 & 6 radial cracks & $\begin{array}{l}9 \text { radial cracks and small spall } \\
\text { area }\end{array}$ & 6 radial cracks \\
\hline 14 & 2 radial cracks & $\begin{array}{l}4 \text { radial cracks and small spall } \\
\text { area }\end{array}$ & 6 radial cracks and loose area \\
\hline 15 & 6 small radial cracks & 8 radial cracks & 7 radial cracks \\
\hline 16 & $\begin{array}{l}4 \text { radial cracks and small } \\
\text { spall area }\end{array}$ & $\begin{array}{l}8 \text { radial cracks and } 2 \text { small spalled } \\
\text { areas }\end{array}$ & 4 radial cracks and small spalled area \\
\hline 17 & 3 small radial cracks & 8 radial cracks and loose area & 8 radial cracks and spall area \\
\hline 18 & Nothing & 9 radial cracks & 9 radial cracks and loose area \\
\hline 19 & 7 small radial cracks & 7 radial cracks and spall area & 8 radial cracks and loose area \\
\hline 20 & $\begin{array}{l}4 \text { radial cracks and loose } \\
\text { area }\end{array}$ & 7 radial cracks and loose area & 11 radial cracks and loose area \\
\hline 21 & Nothing & 8 radial cracks & 8 radial cracks \\
\hline
\end{tabular}




\section{Hardness Testing}

The specimens were all tested for hardness using a Rockwell $15 \mathrm{~N}$ superficial hardness scale. The superficial scale was used because of the lighter indenter loads used for the tests. The $15 \mathrm{~N}$ scale can be approximately converted to the $\mathrm{C}$ scale. All specimens were tested at three areas along the length of the rod and averaged. Specimen 17 had the lowest hardness number at $81.06(-42 \mathrm{Rc})$. Specimen 8 had the highest hardness number at 95.06 ( $\sim 76 \mathrm{Rc})$. The average hardness for the specimens with the alumina top coating were all within three hardness numbers of each other except specimen 17, which had a molybdenum bond coat. The average hardness for specimens with the pure chromia top coat were all within two hardness numbers of each other. The Rexroth samples had a hardness number within the range for the alumina coated samples. The indenter used for the hardness testing did not cause damage to any of the coatings tested. The specimens that had Rockwell $15 \mathrm{~N}$ hardness over 93 meet the current specification. Only specimens $7,8,9,10,11$, and 16 had hardness numbers over the minimum.

Table 6. Results of the hardness testing of the samples.

\begin{tabular}{|c|c|c|}
\hline $\begin{array}{c}\text { Specimen } \\
\text { No. }\end{array}$ & $\begin{array}{c}\text { Rockwell 15N } \\
\text { Superficial Hardness } \\
\text { No. }\end{array}$ & Average \\
\hline 1 & $88.8,90.0,89.8$ & 89.53 \\
\hline 2 & $89.6,91.1,88.4$ & 89.70 \\
\hline 3 & $86.6,87.9,87.7$ & 87.23 \\
\hline 4 & $86.2,87.0,87.0$ & 86.73 \\
\hline 5 & $88.6,90.0,89.8$ & 89.13 \\
\hline 6 & $90.0,90.2,91.0$ & 90.40 \\
\hline 7 & $93.4,93.6,93.2$ & 93.40 \\
\hline 8 & $94.8,95.2,95.2$ & 95.06 \\
\hline 9 & $92.4,93.6,93.4$ & 93.13 \\
\hline 10 & $92.6,94.4,93.8$ & 93.60 \\
\hline 11 & $92.5,94.1,93.6$ & 93.40 \\
\hline 12 & $88.6,89.0,90.9$ & 89.56 \\
\hline 13 & $89.8,91.0,90.2$ & 90.33 \\
\hline 14 & $91.8,92.8,92.6$ & 92.40 \\
\hline 15 & $91.0,91.4,91.2$ & 91.20 \\
\hline 16 & $94.4,95.2,94.2$ & 94.60 \\
\hline 17 & $81.4,80.4,81.4$ & 81.06 \\
\hline 18 & $87.0,88.0,88.2$ & 87.73 \\
\hline 19 & $90.2,90.2,90.4$ & 90.26 \\
\hline 20 & $86.0,86.8,88.8$ & 87.20 \\
\hline 21 & $88.0,88.4,88.0$ & 88.13 \\
\hline
\end{tabular}




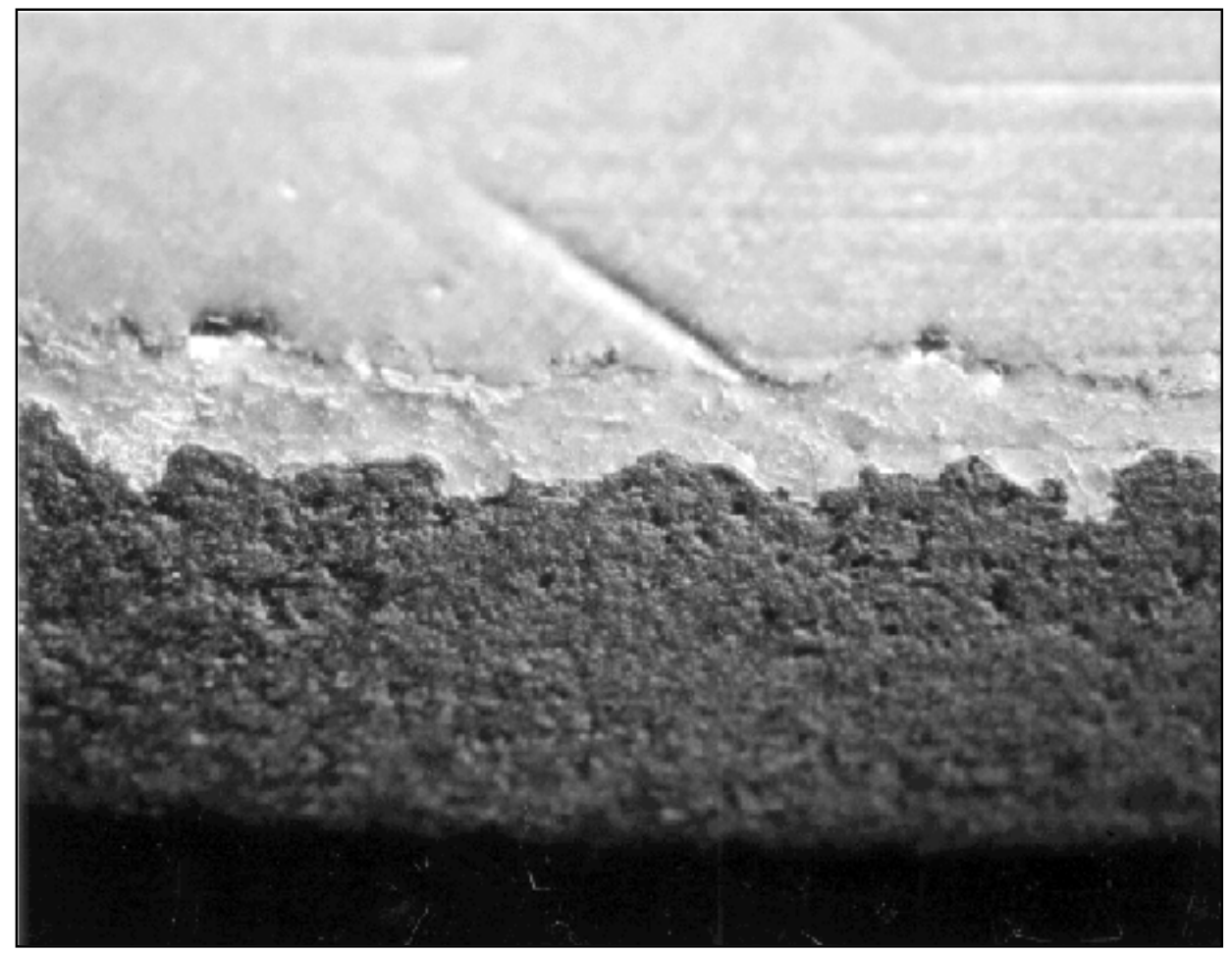

Figure 1. Cross section of alumina-13\% titania coating with nickel-chrome interlayer and no seal coat (Specimen 1).

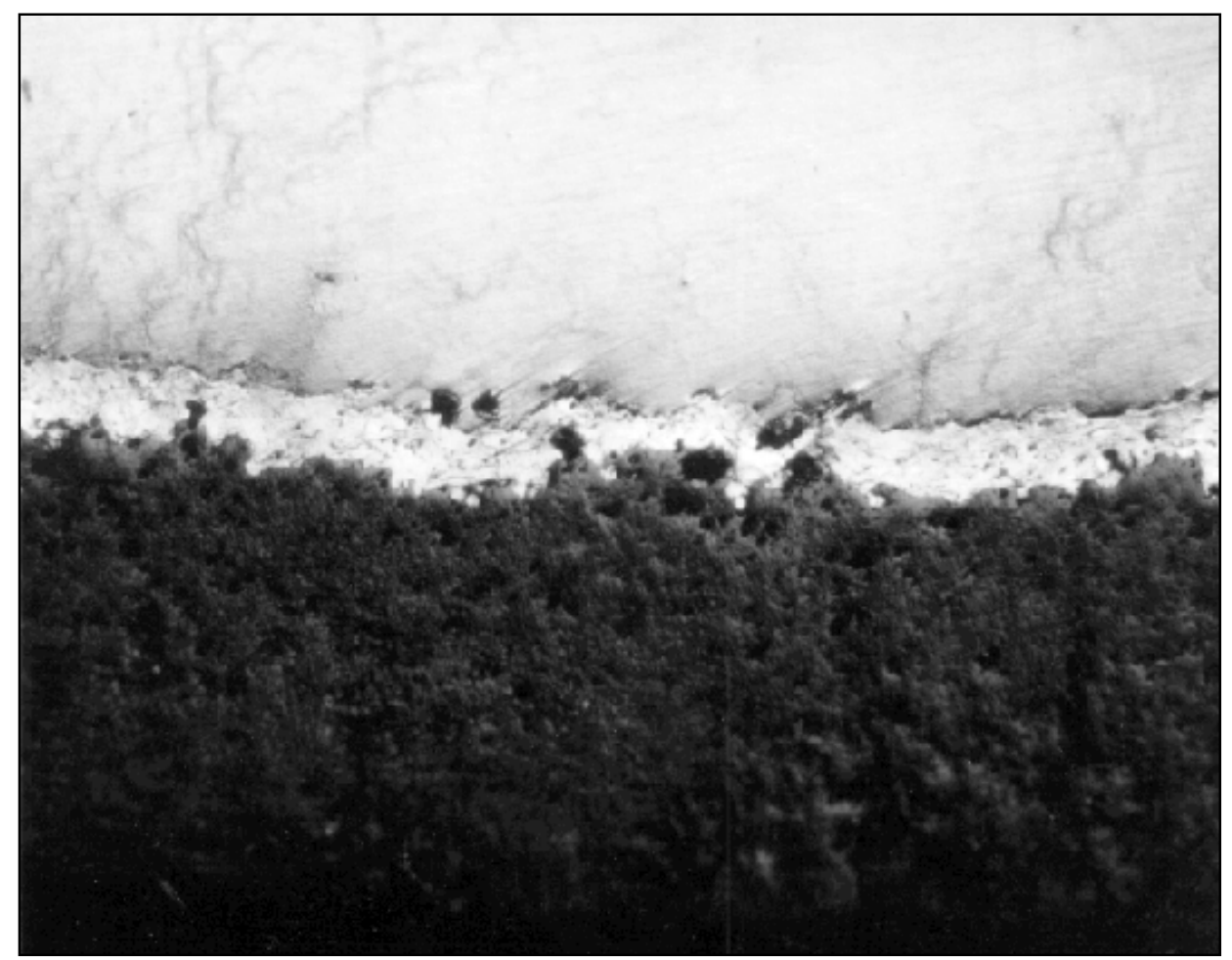

Figure 2. Cross section of alumina-13\% titania coating with nickel-chrome interlayer and seal coat (Specimen 2). 


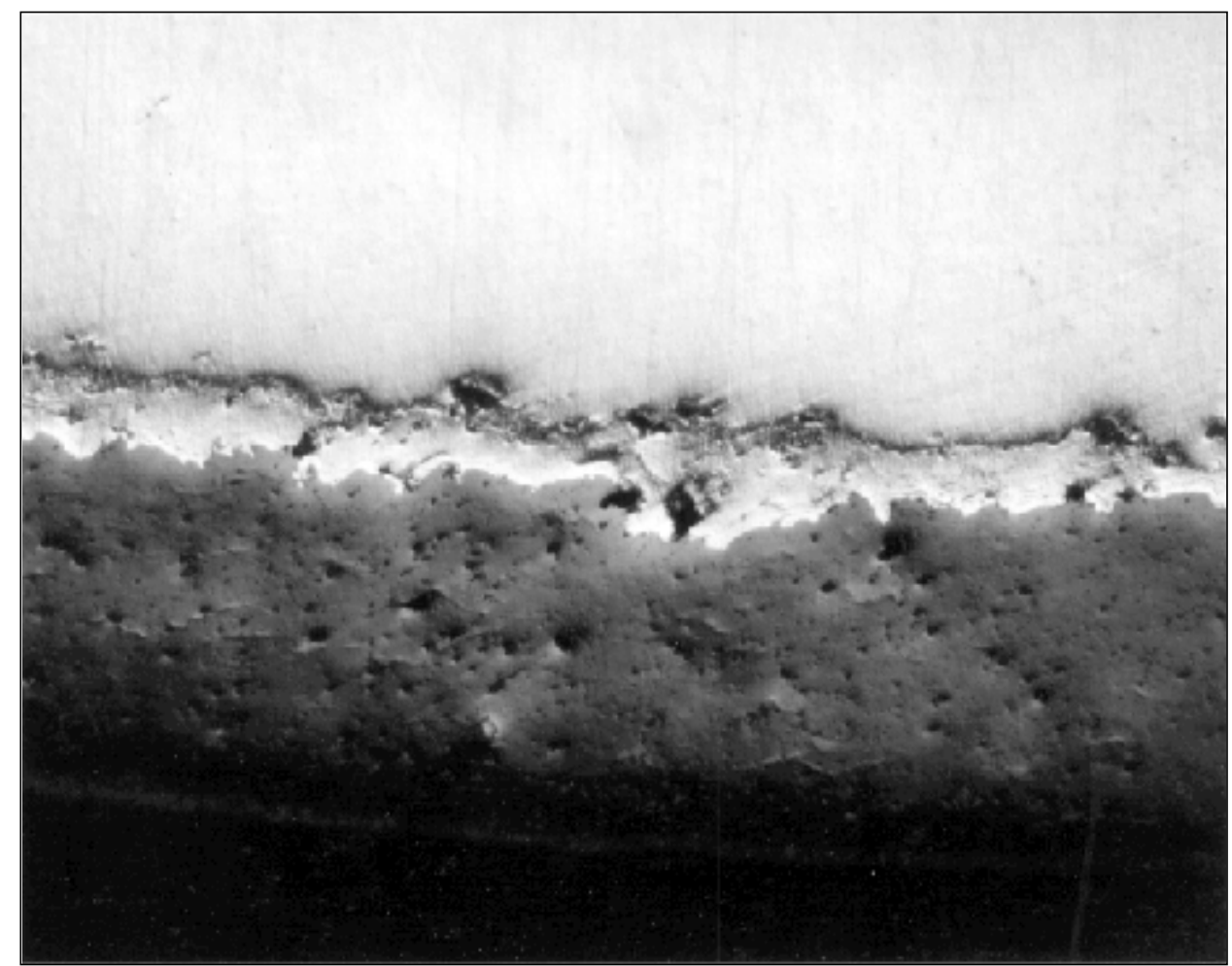

Figure 3. Cross section of alumina- $40 \%$ titania coating with nickel-chrome interlayer and no seal coat (Specimen 3).

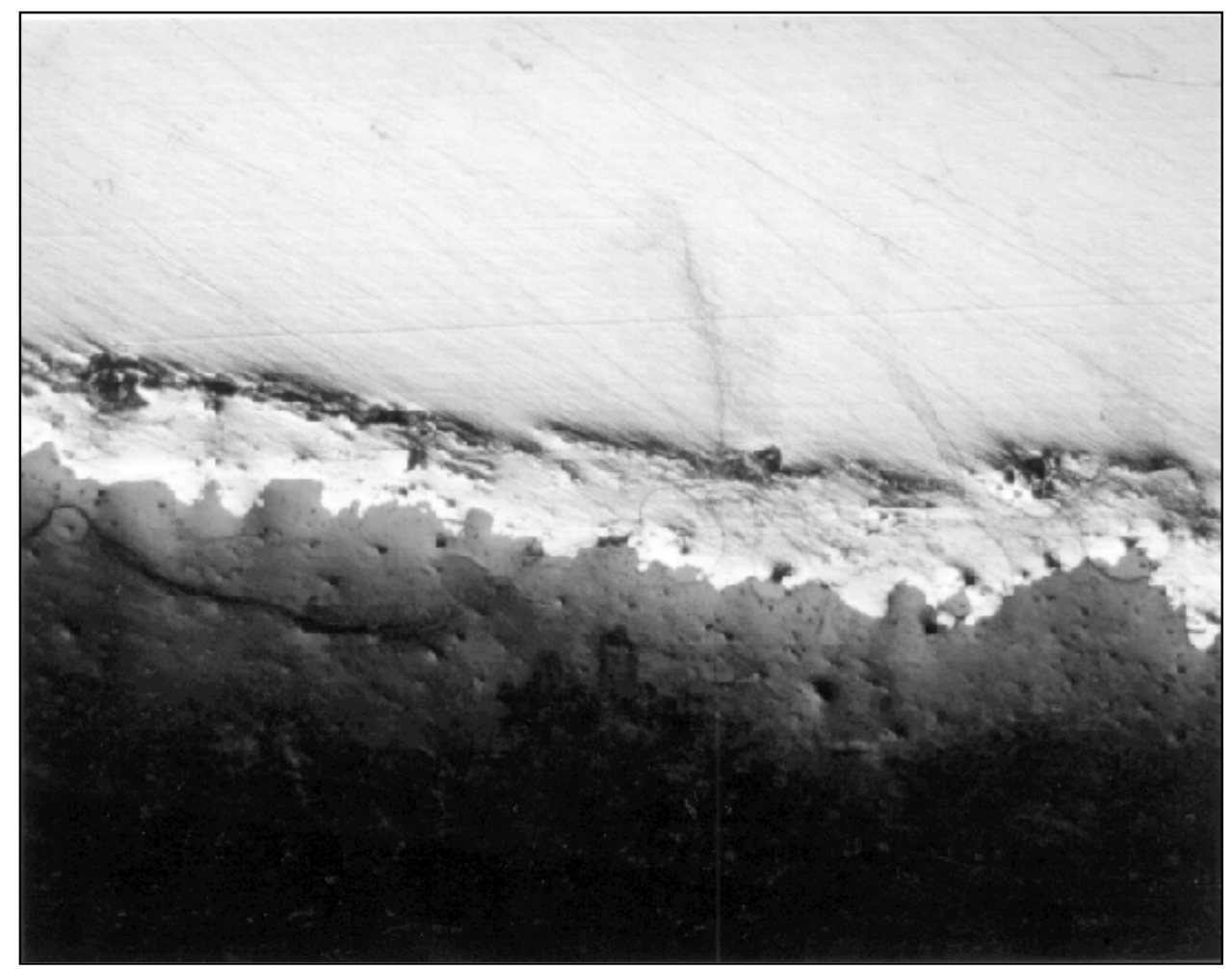

Figure 4. Cross section of alumina-40\% titania coating with nickel-chrome interlayer and seal coat (Specimen 4). 


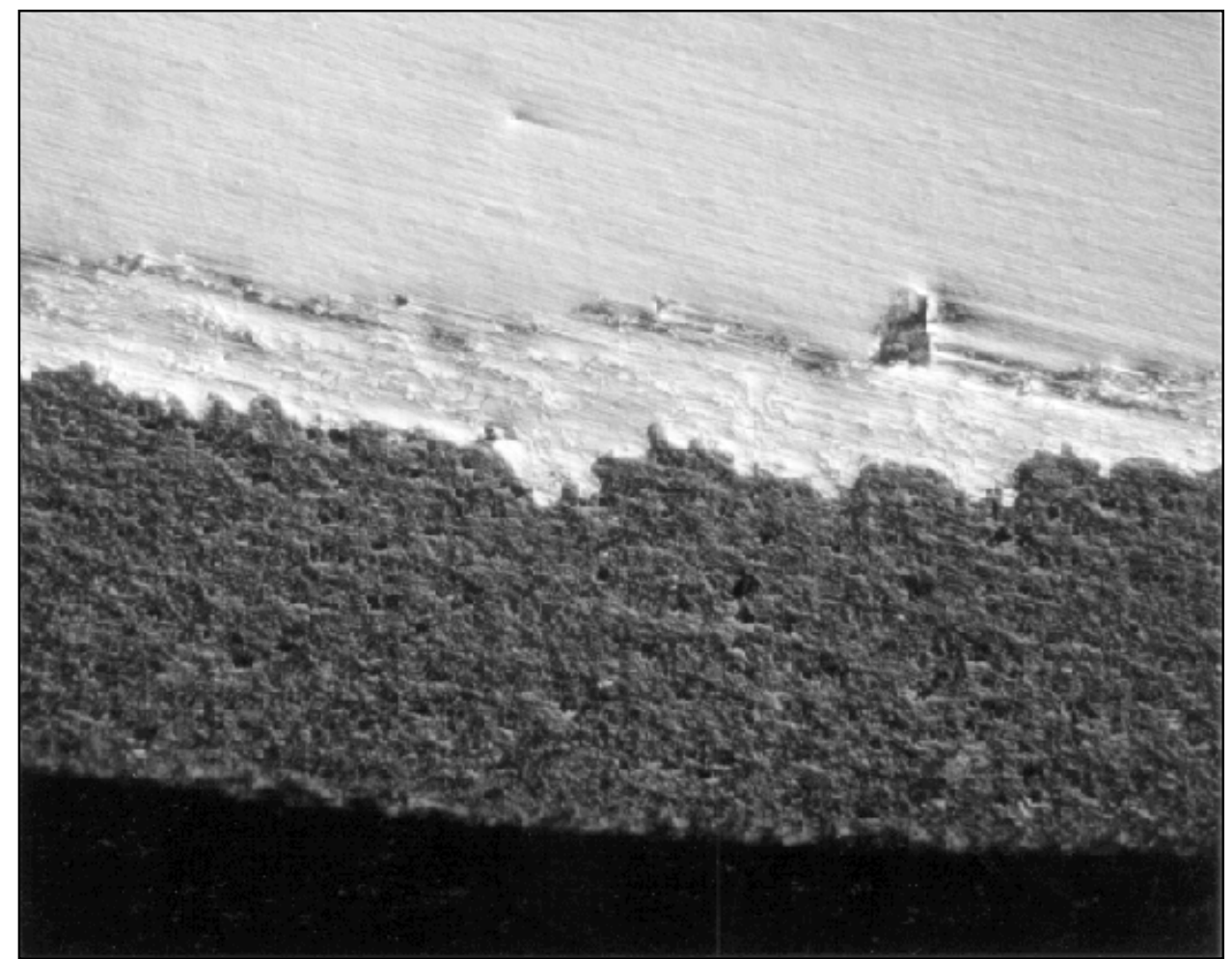

Figure 5. Cross section of alumina-13\% titania coating with nickel-chrome interlayer and no seal coat (Specimen 5).

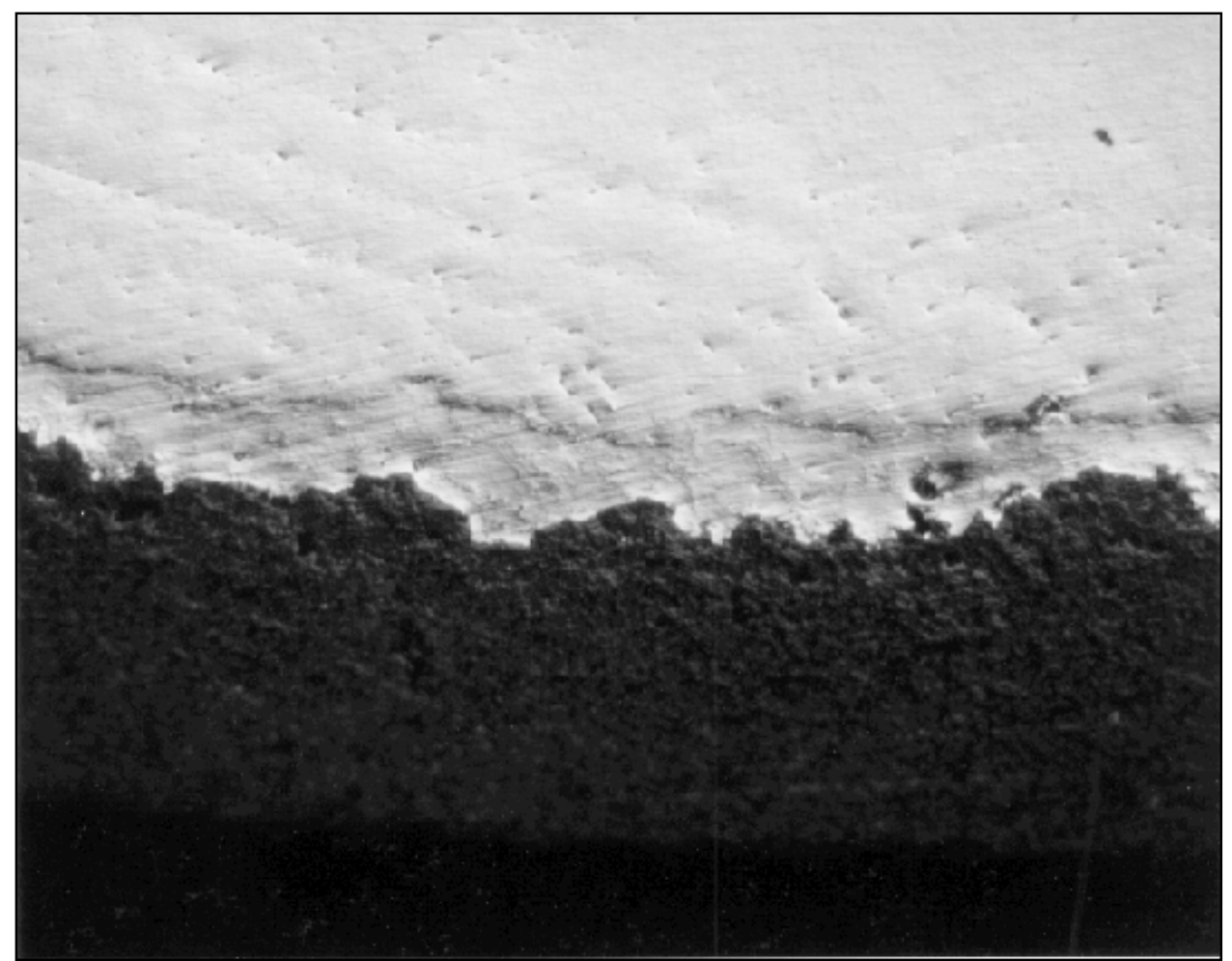

Figure 6. Cross section of alumina-13\% titania coating with nickel-chrome interlayer and seal coat (Specimen 6). 


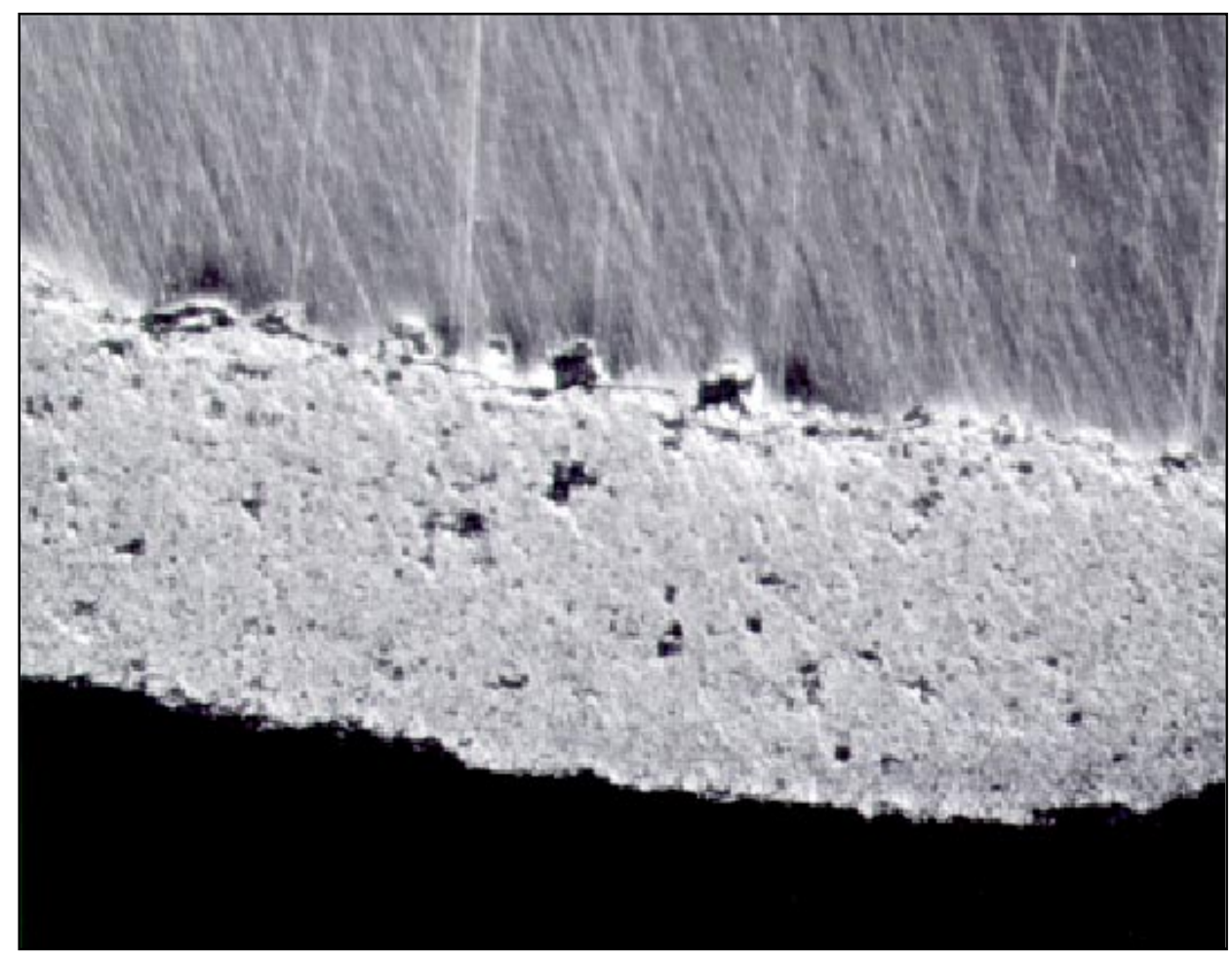

Figure 7. Cross section of chromia coating with no interlayer and no seal coat (Specimen 7).

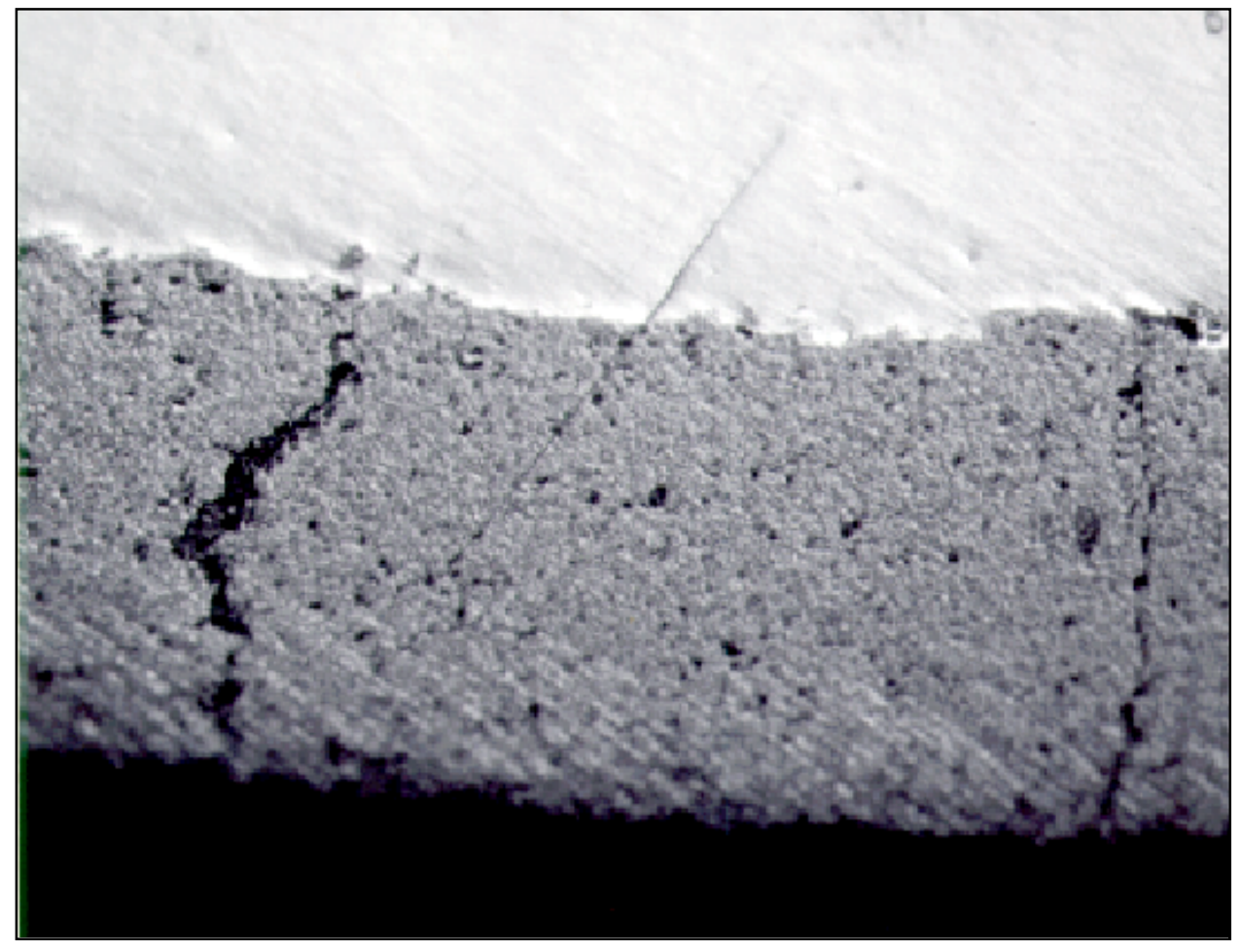

Figure 8. Cross section of chromia coating with no interlayer and no seal coat (Specimen 8). 


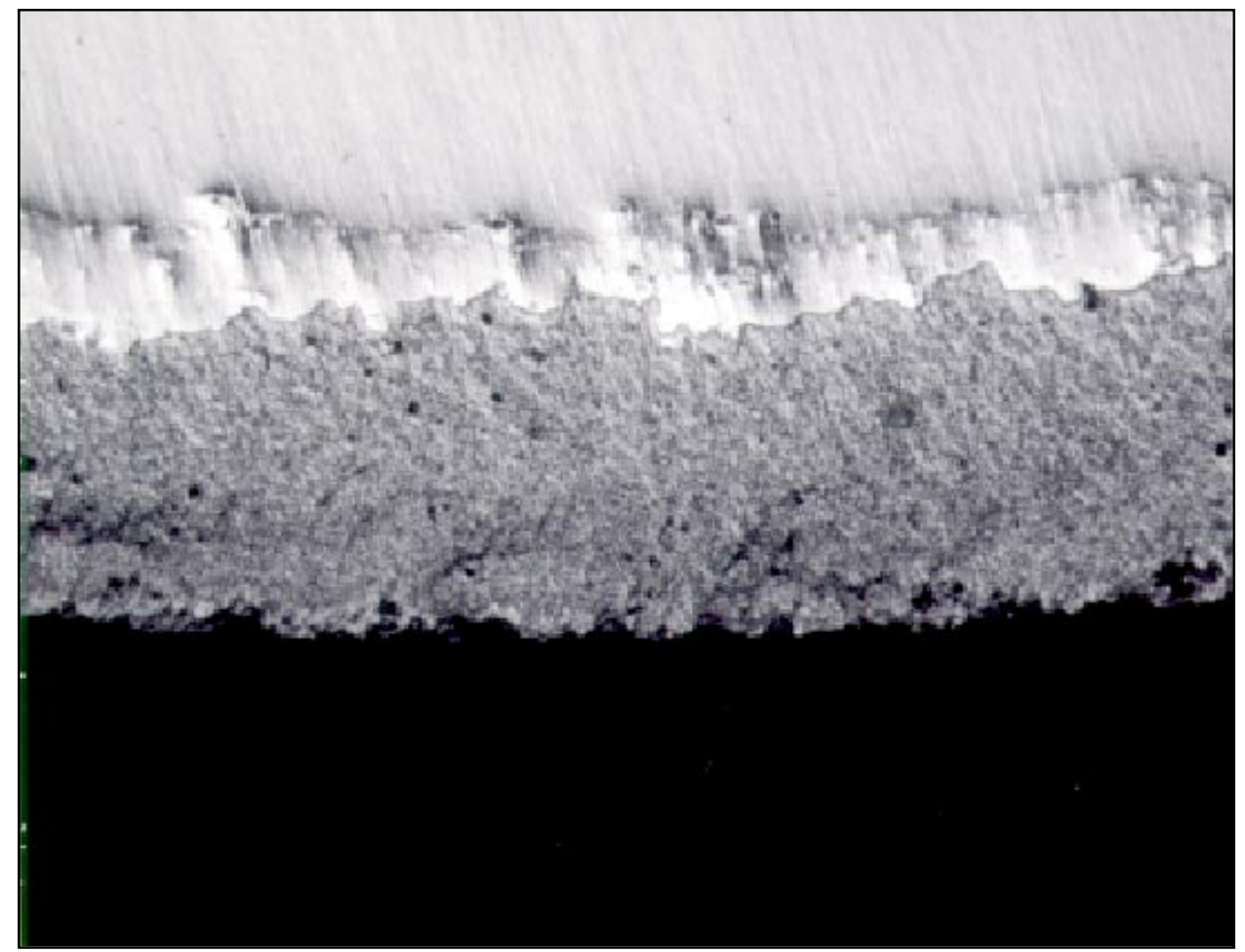

Figure 9. Cross section of chromia coating with nickel-chrome interlayer and seal coat (Specimen 9).

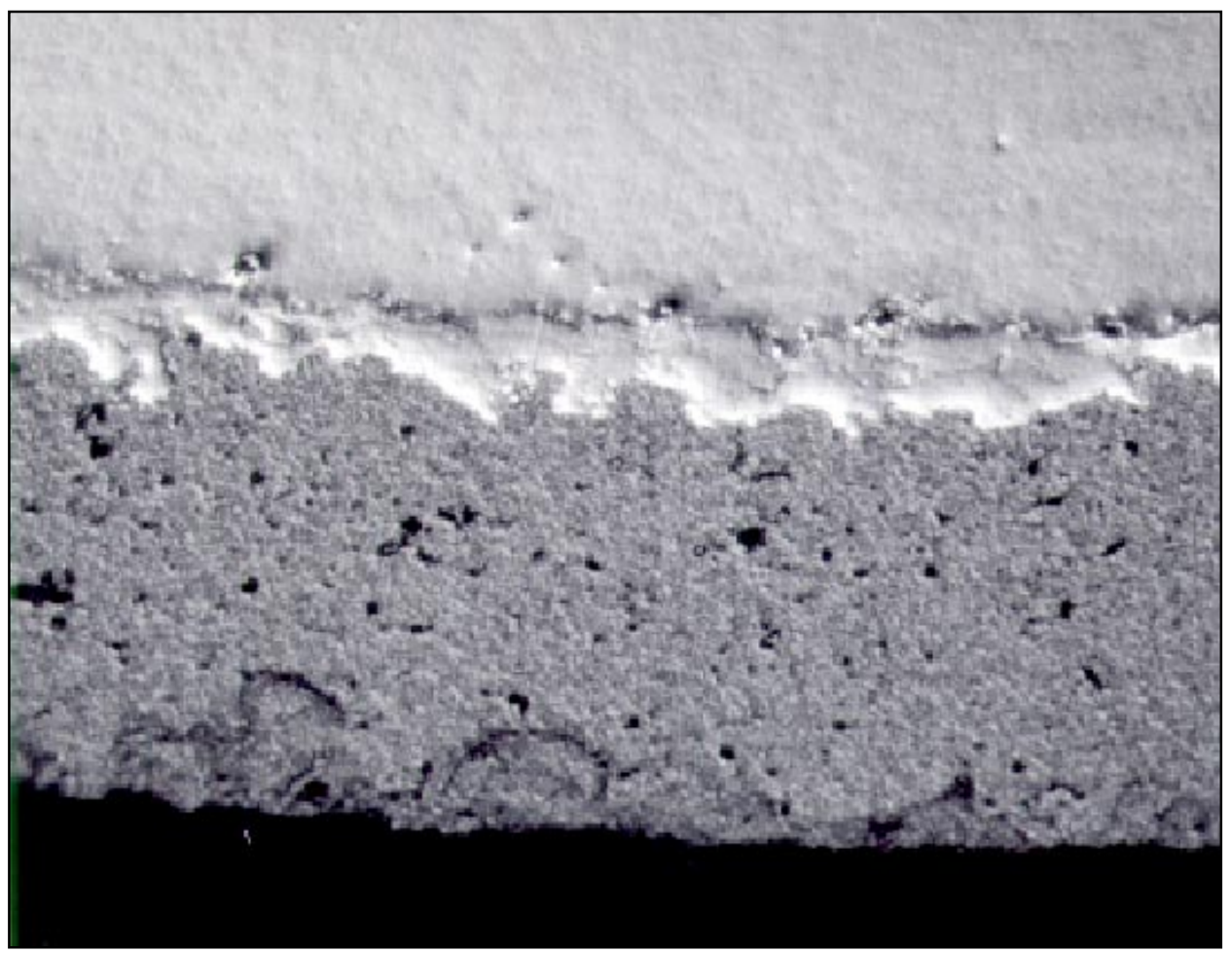

Figure 10. Cross section of chromia coating with nickel-aluminum interlayer and seal coat (Specimen 10). 


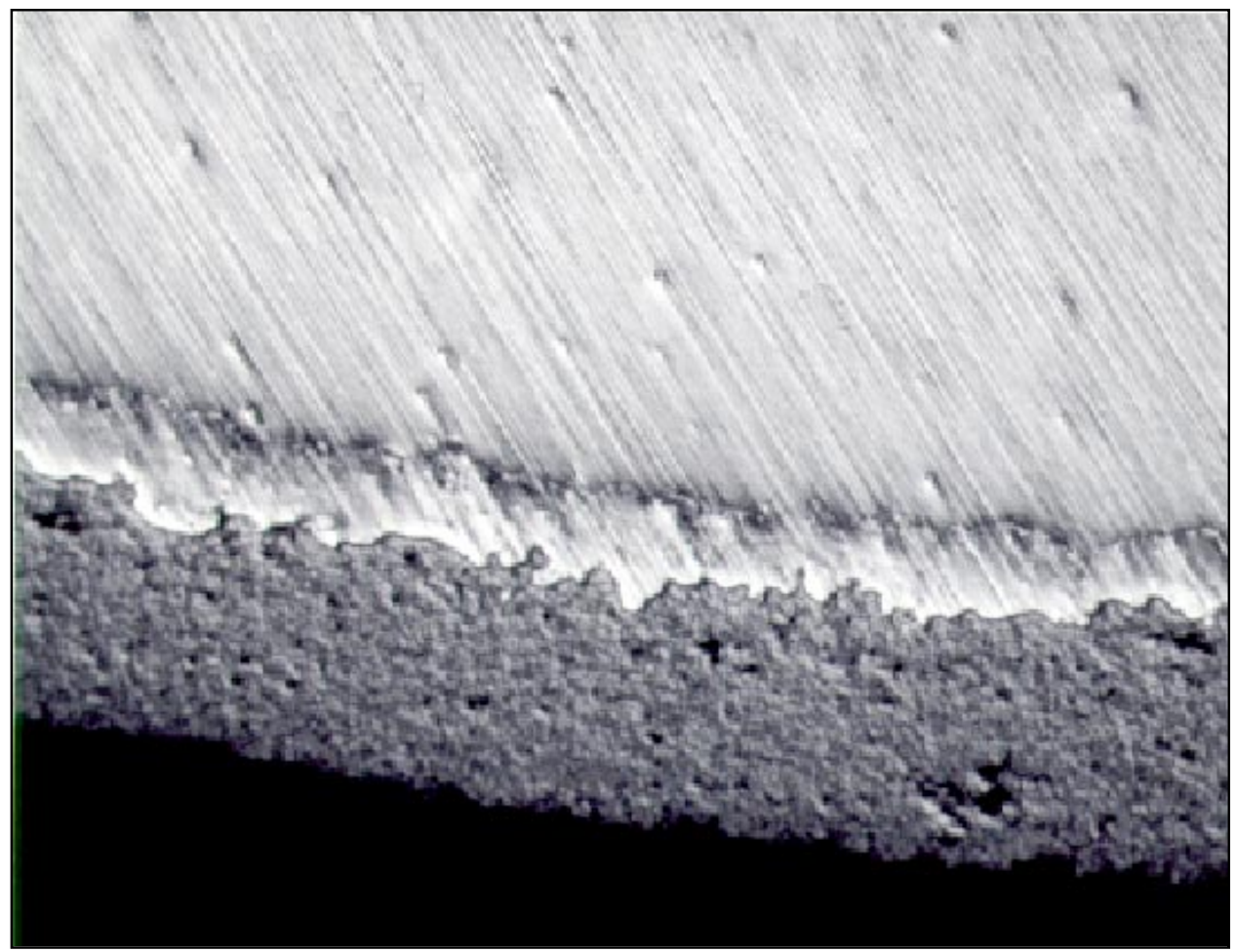

Figure 11. Cross section of chromia coating with nickel-chrome interlayer and no seal coat (Specimen 11).

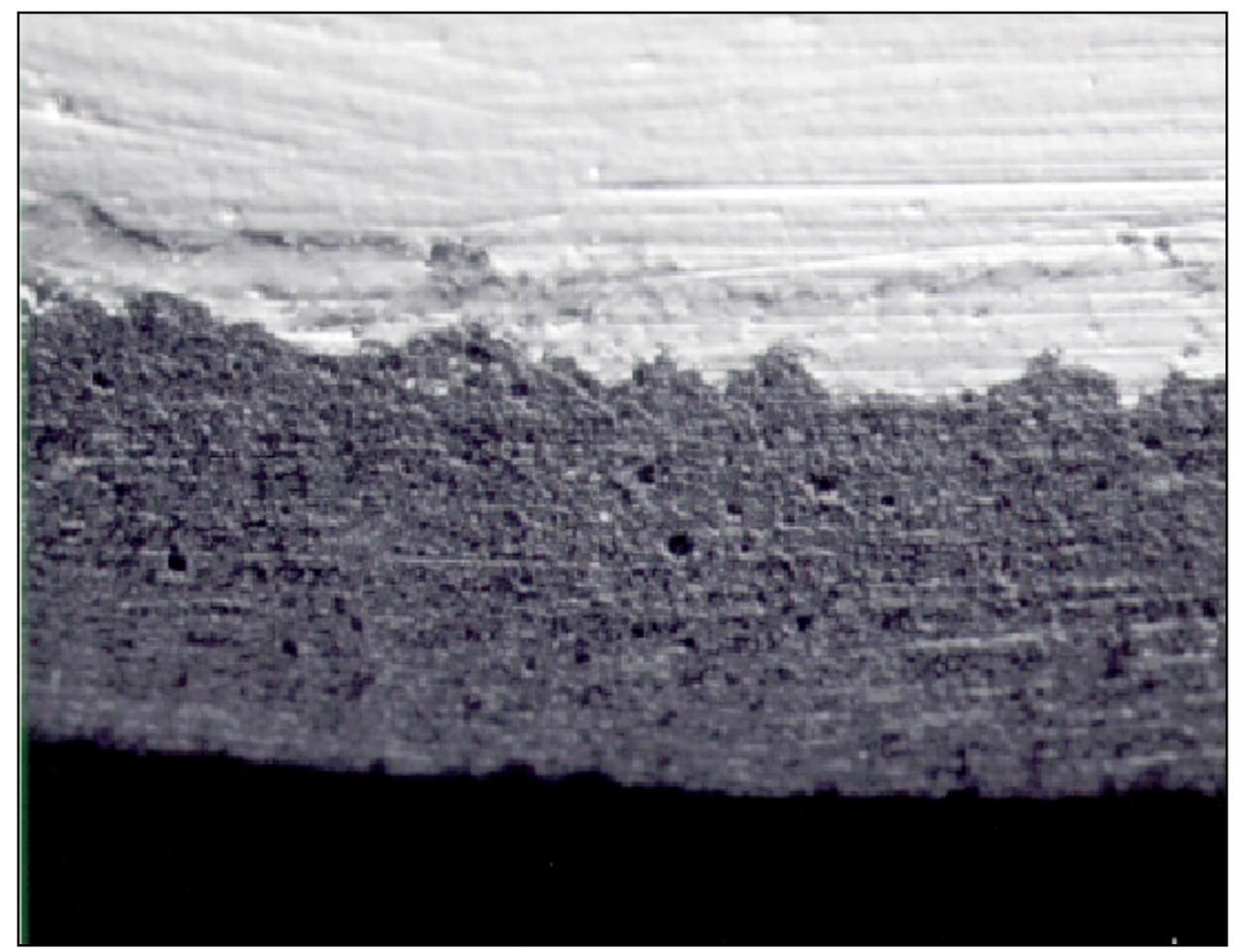

Figure 12. Cross section of alumina- $13 \%$ titania coating with nickel-aluminum HVOC interlayer and no seal coat (Specimen 12). 


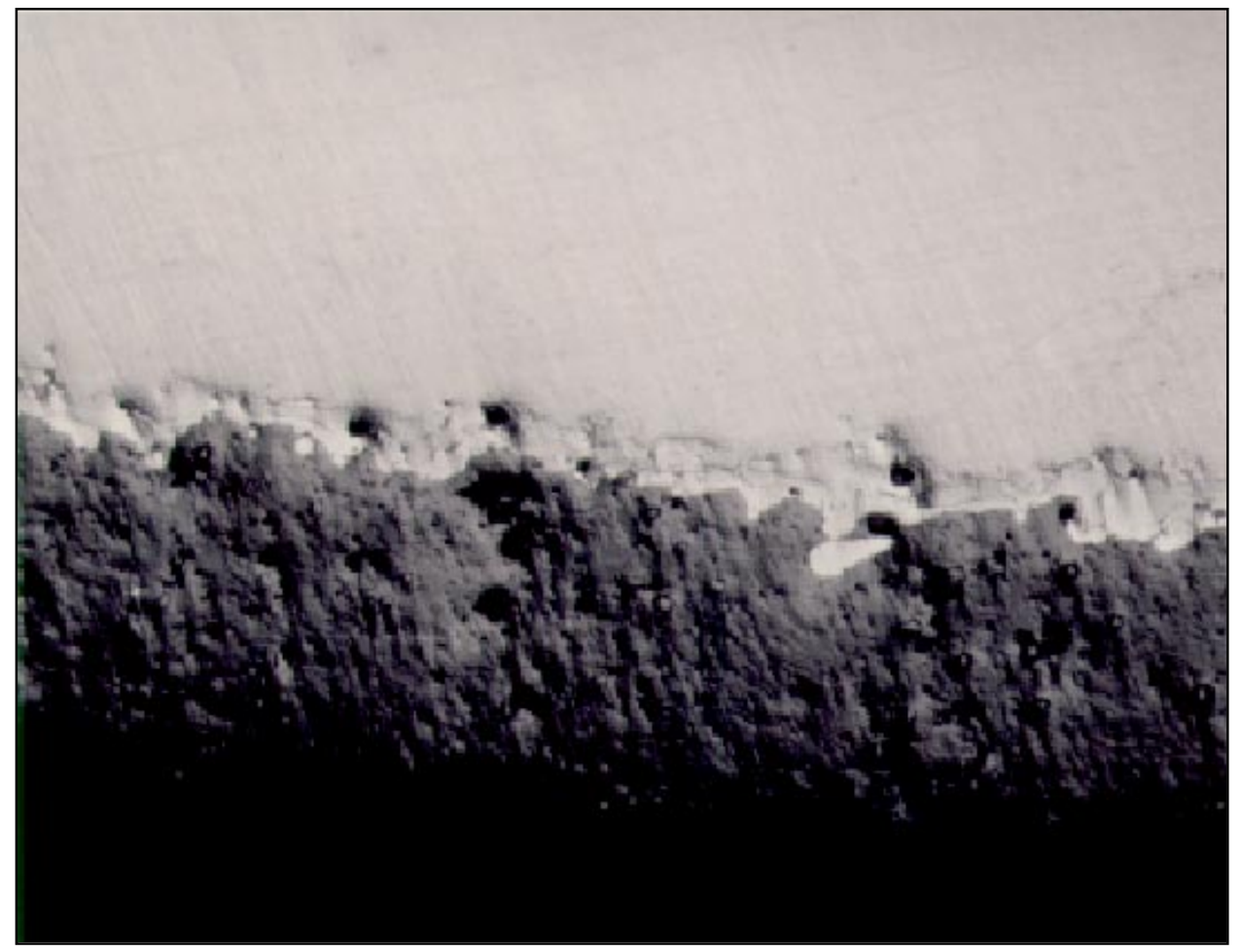

Figure 13. Cross section of alumina-13\% titania with nickel-aluminum two-wire arc interlayer and no seal coat (Specimen 13).

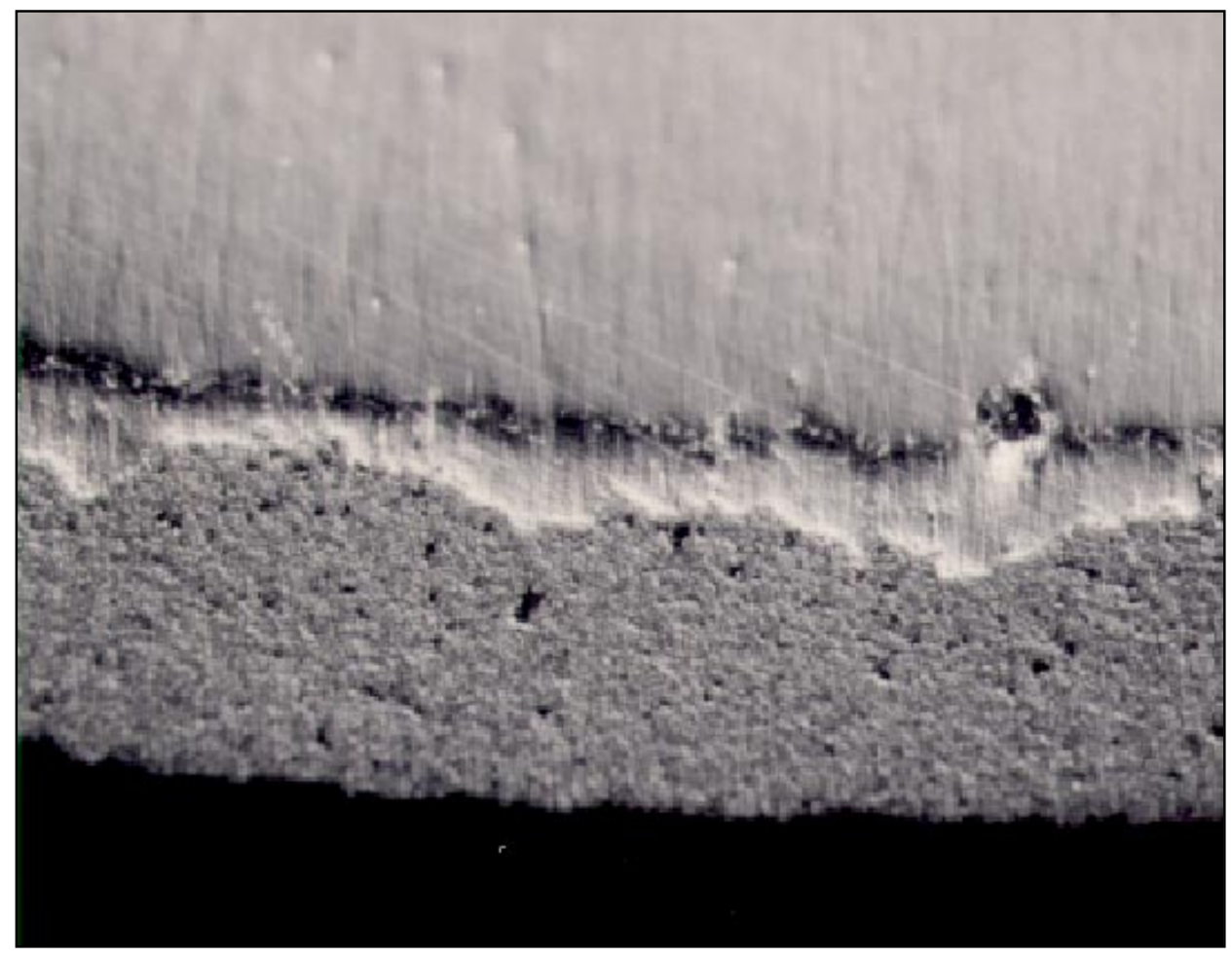

Figure 14. Cross section of chromia-5\% silica-3\% titania coating with nickelchrome interlayer and no seal coat (Specimen 14). 


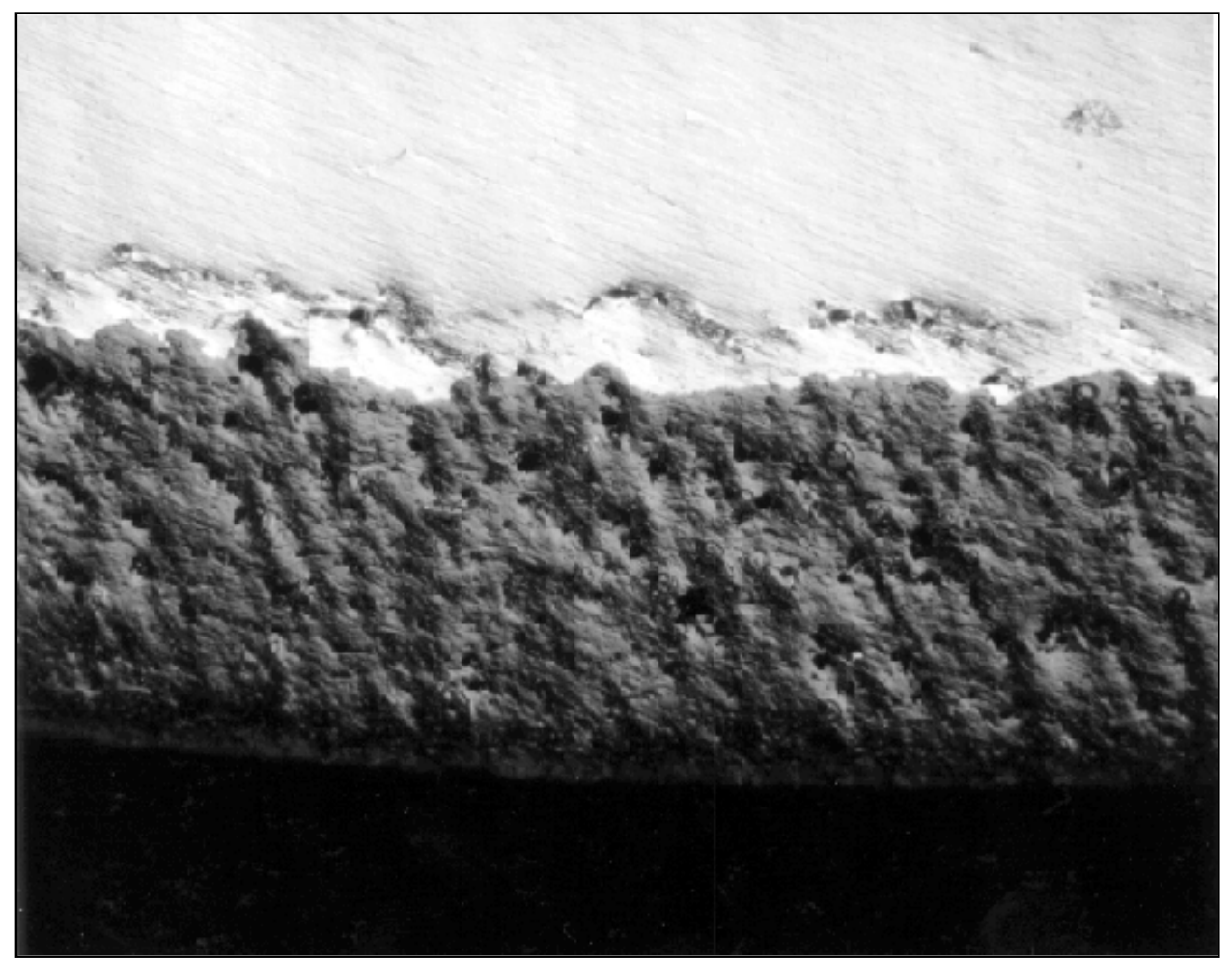

Figure 15. Cross section of alumina-13\% titania coating with 316 stainless steel interlayer and no seal coat (Specimen 15).

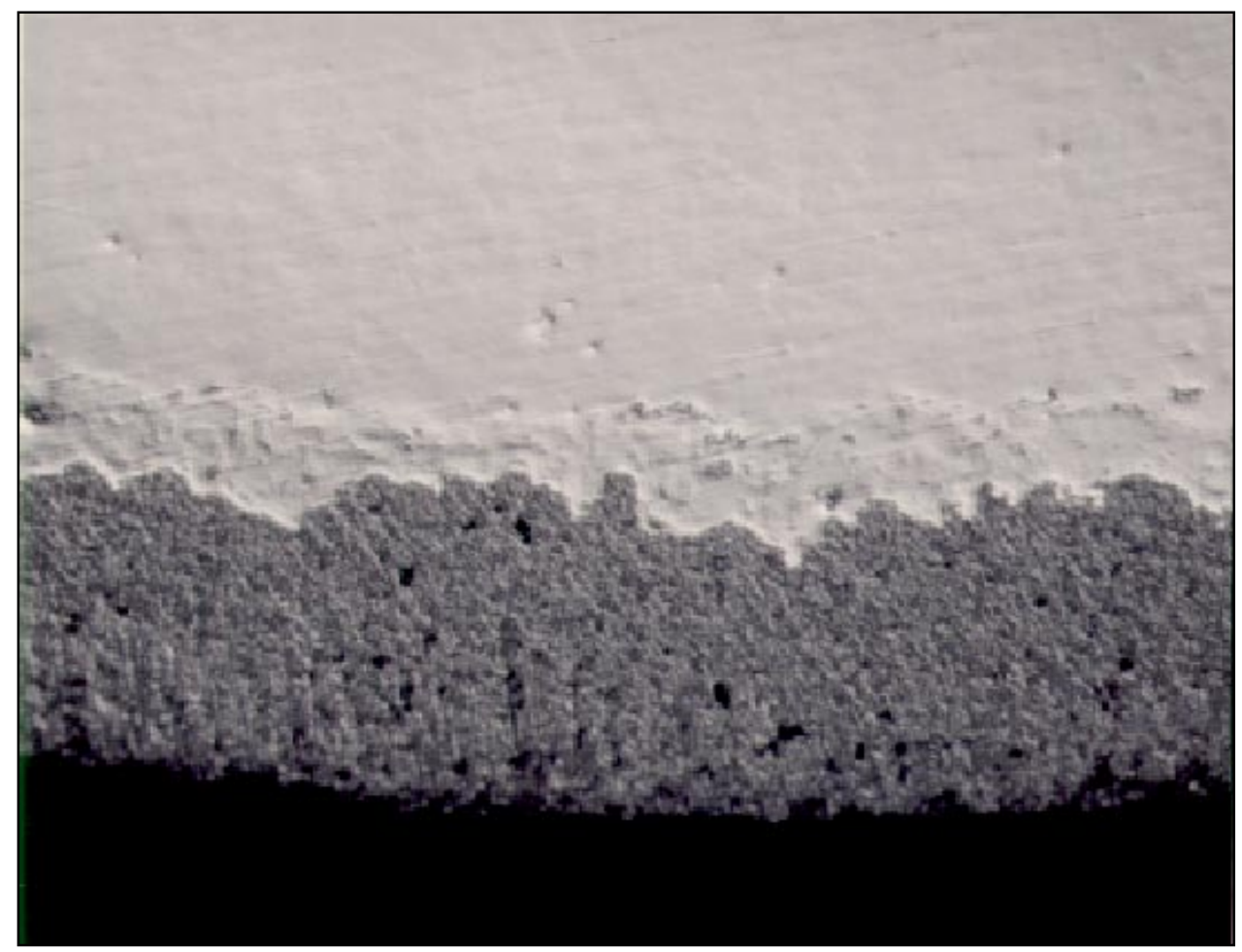

Figure 16. Cross section of chromia coating with $\mathbf{4 0 0}$ series stainless steel interlayer and no seal coat (Specimen 16). 


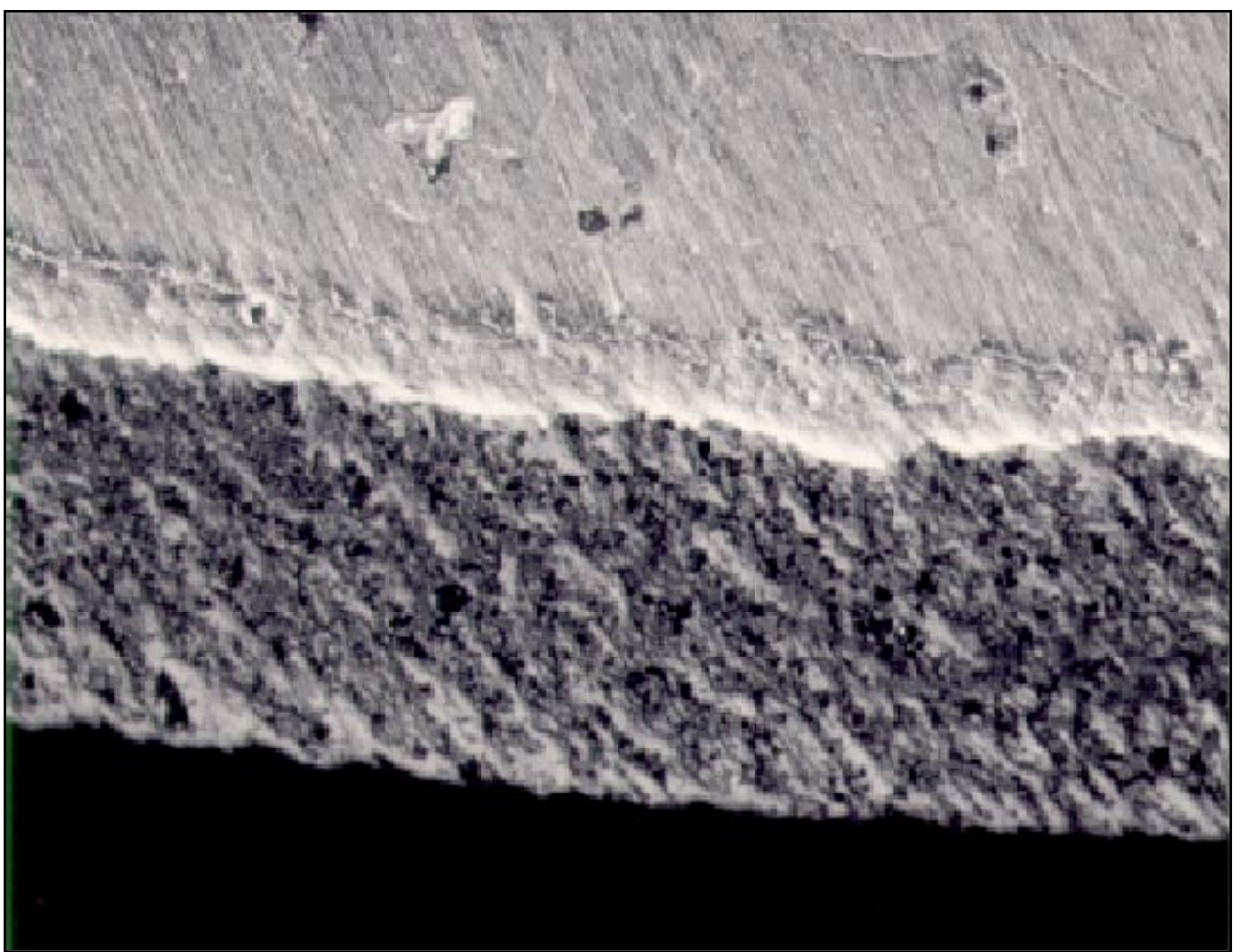

Figure 17. Cross section of alumina- $40 \%$ titania coating with molybdenum interlayer and no seal coat (Specimen 17).

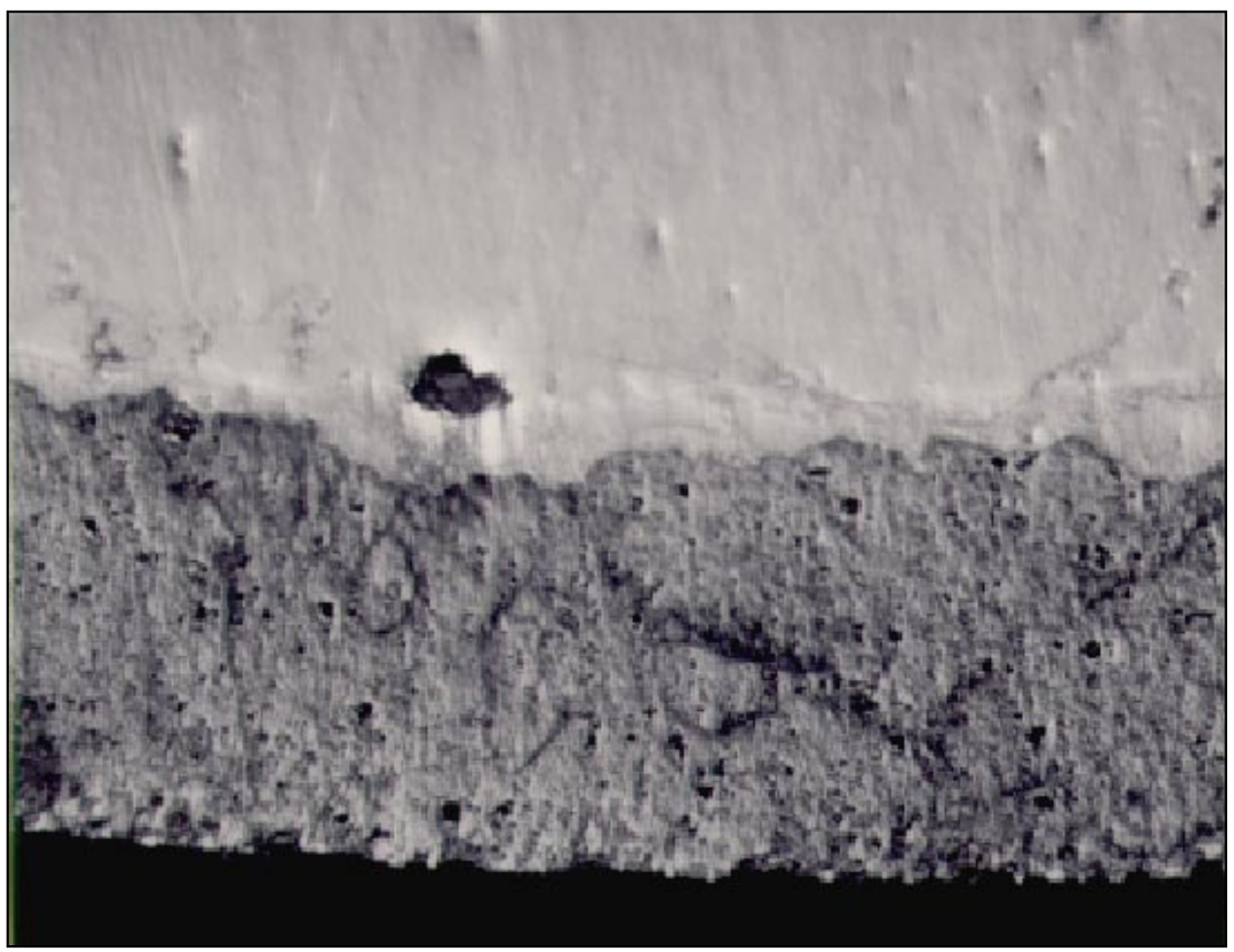

Figure 18. Cross section of titania coating with nickel-chrome interlayer and seal coat (Specimen 18). 


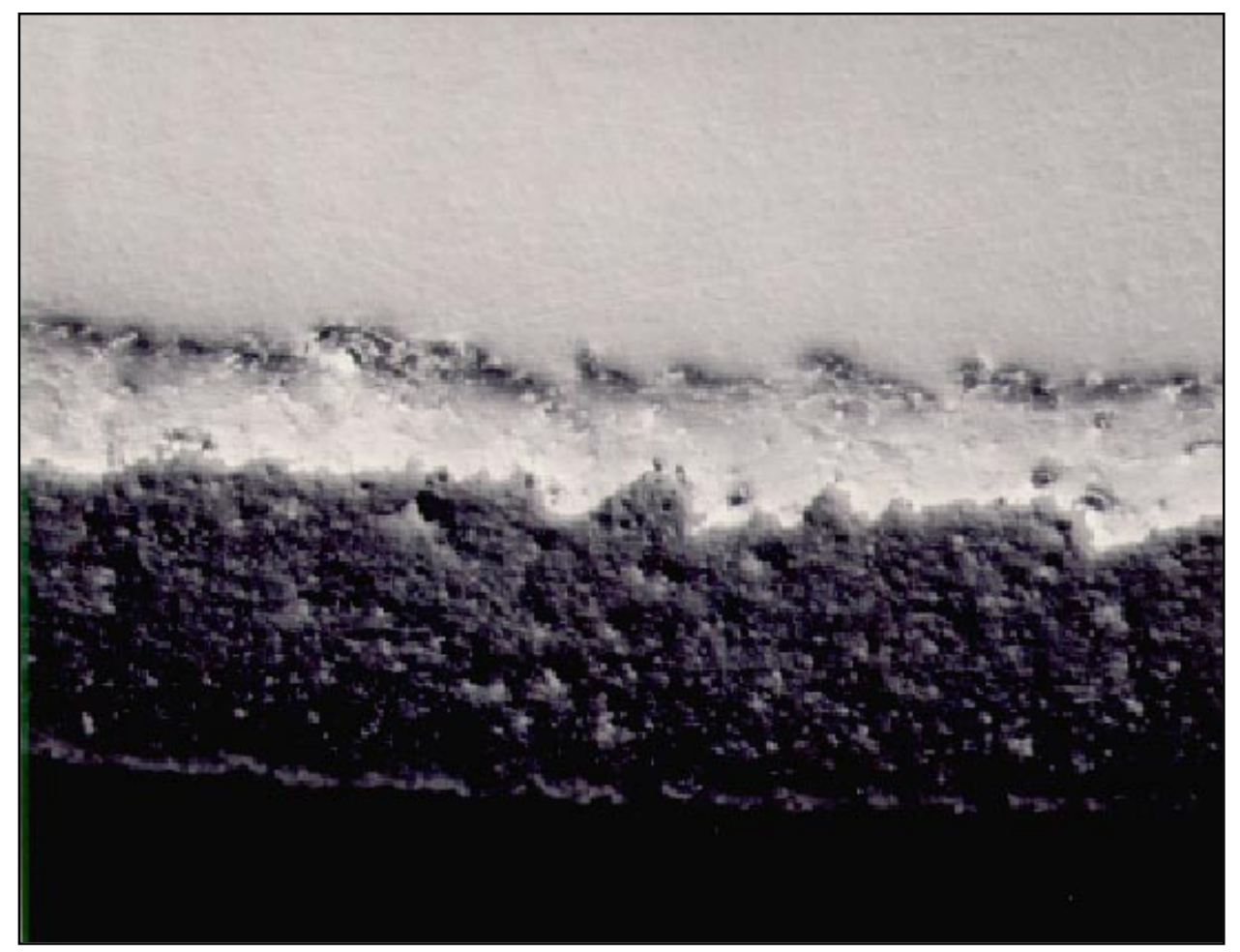

Figure 19. Cross section of alumina-3\% titania coating with nickel-chrome interlayer and no seal coat (Specimen 19).

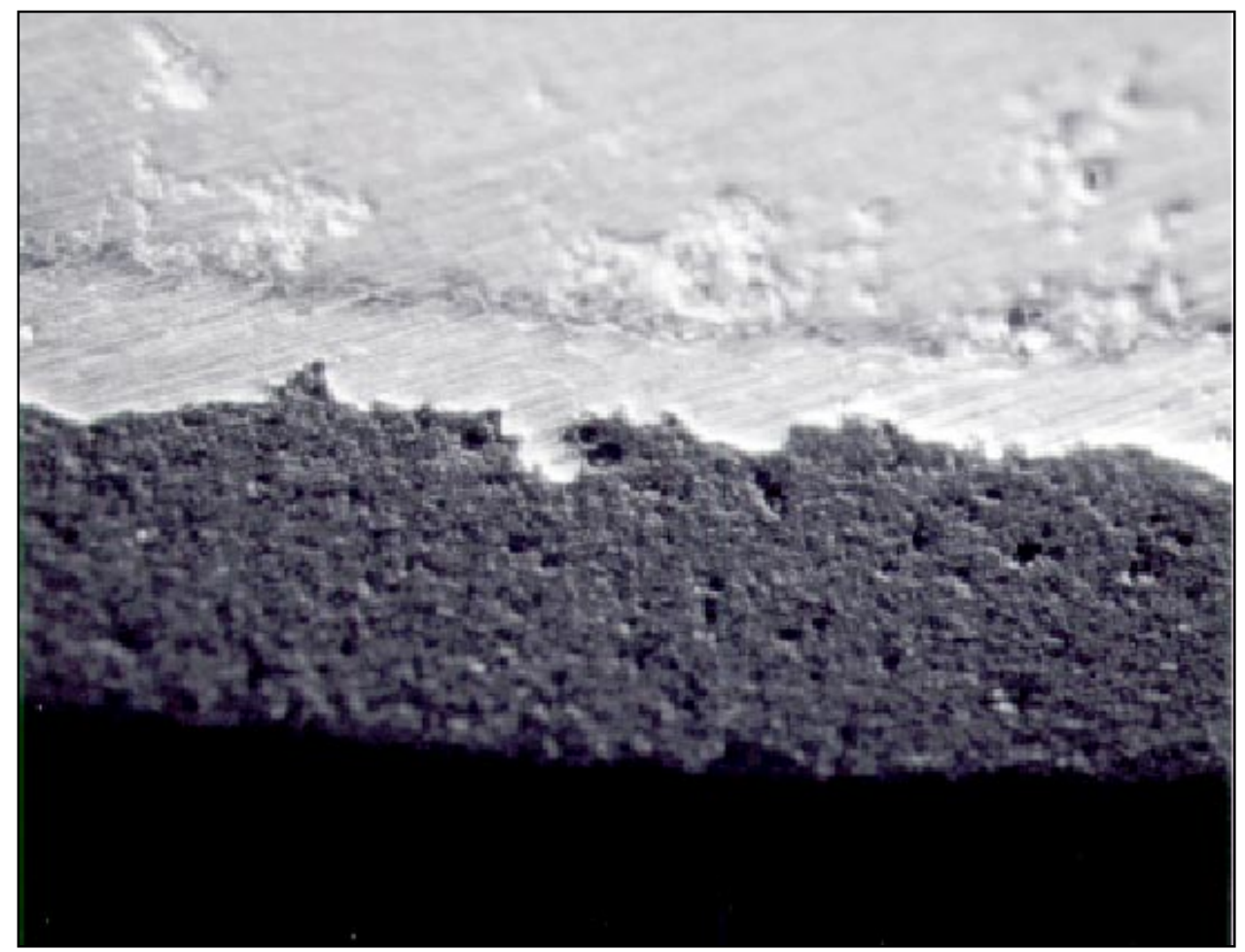

Figure 20. Cross section of alumina-13\% titania coating with aluminum bronze interlayer and no seal coat (Specimen 20). 


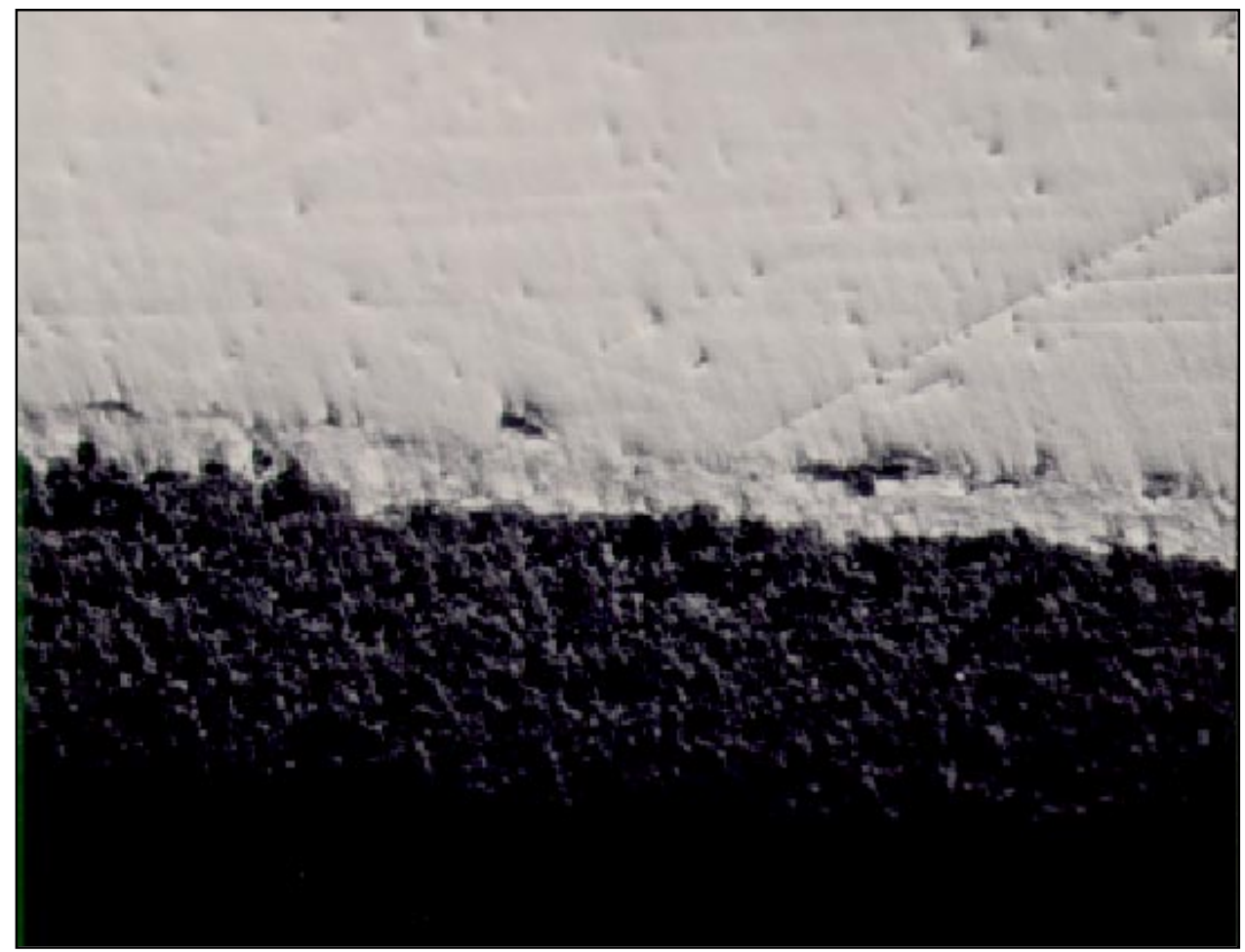

Figure 21. Cross section of the Rex Roth proprietary coating sample (Specimen 21).

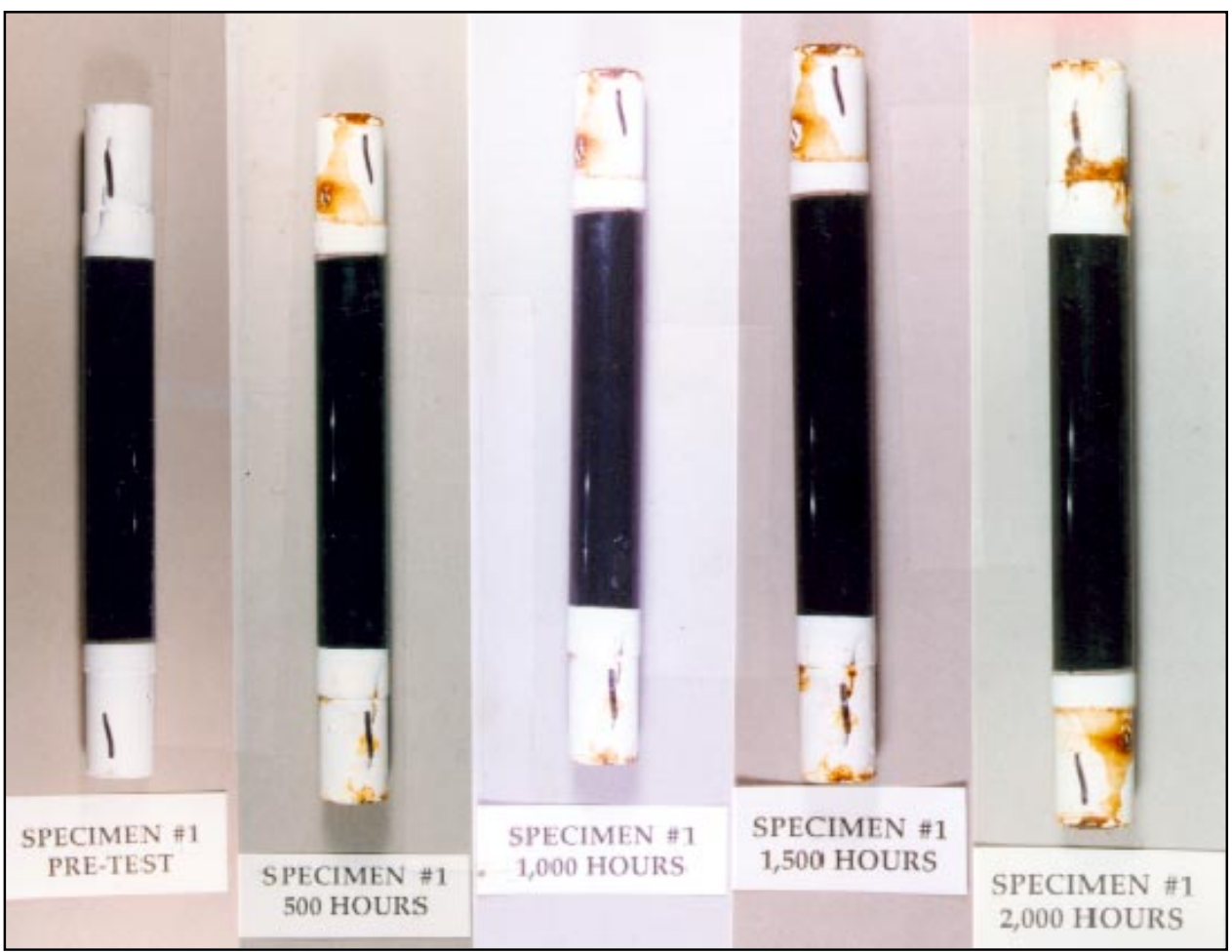

Figure 22. Specimen \#1 showing the results of the salt spray test. 


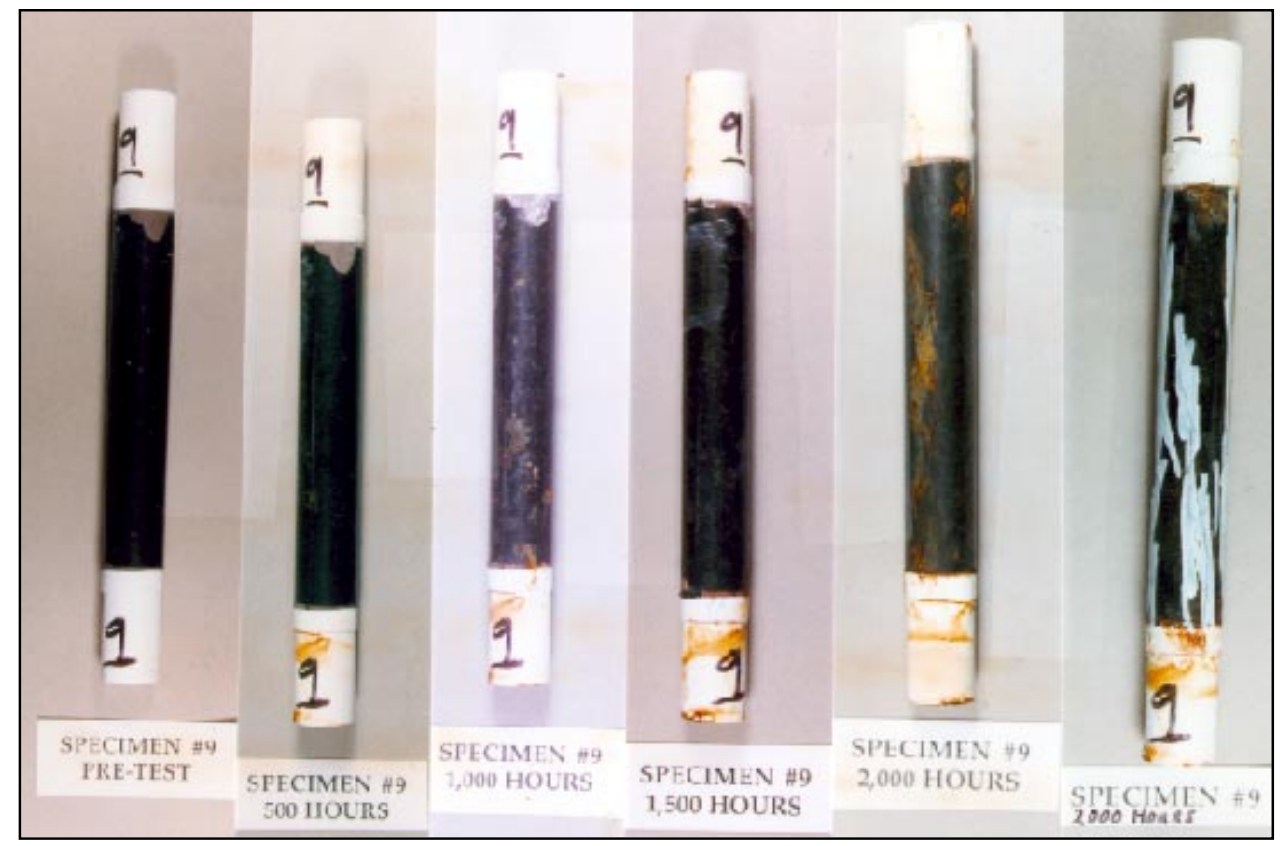

Figure 23. Specimen \#9 showing the results of the salt spray test; the last frame shows the cracks outlined in white. 

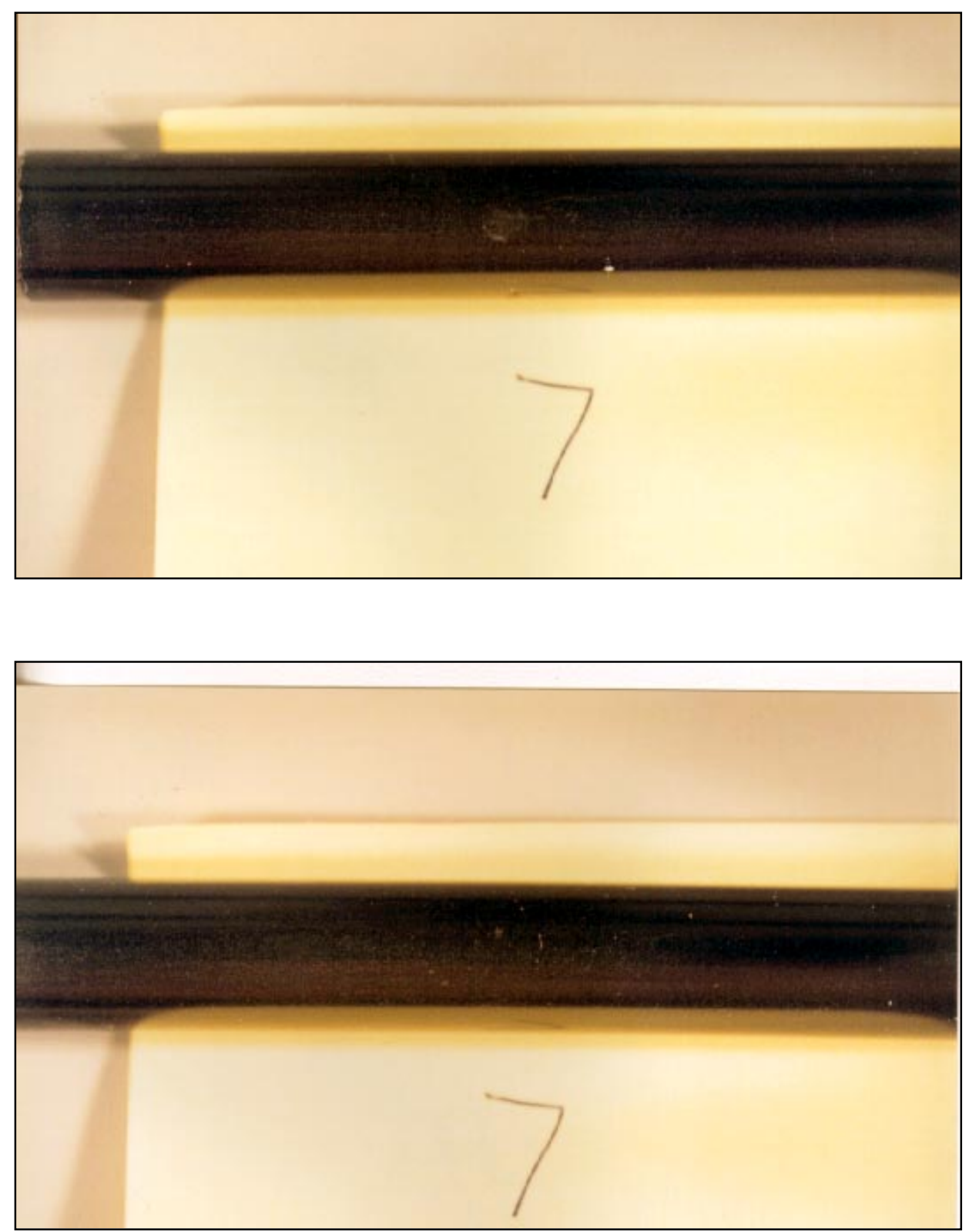

Figure 24. Specimen \#7 bend test sample showing compression side (top) and tension side (bottom). 

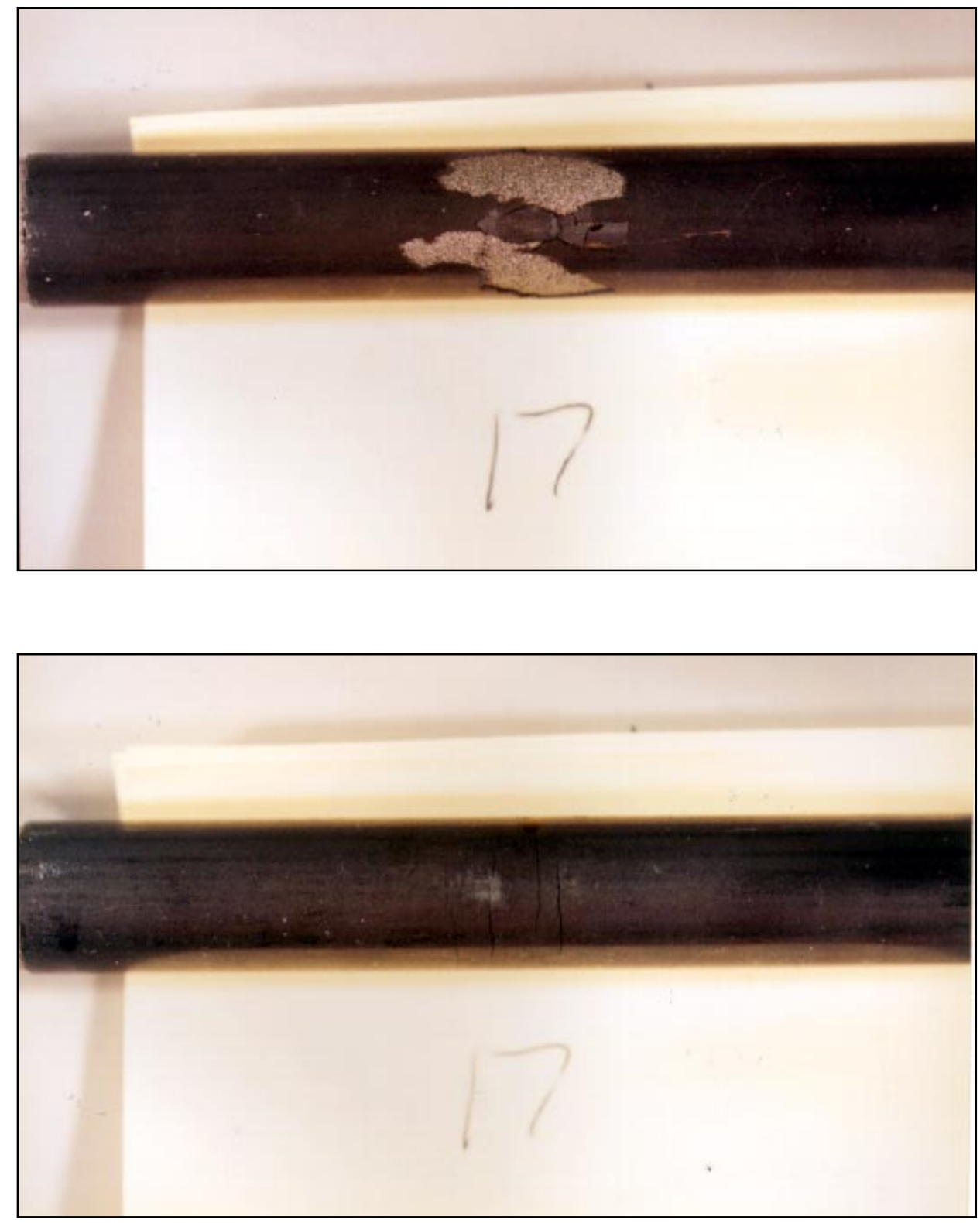

Figure 25. Specimen \#17 bend test sample showing compression side (top) and tension side (bottom). 


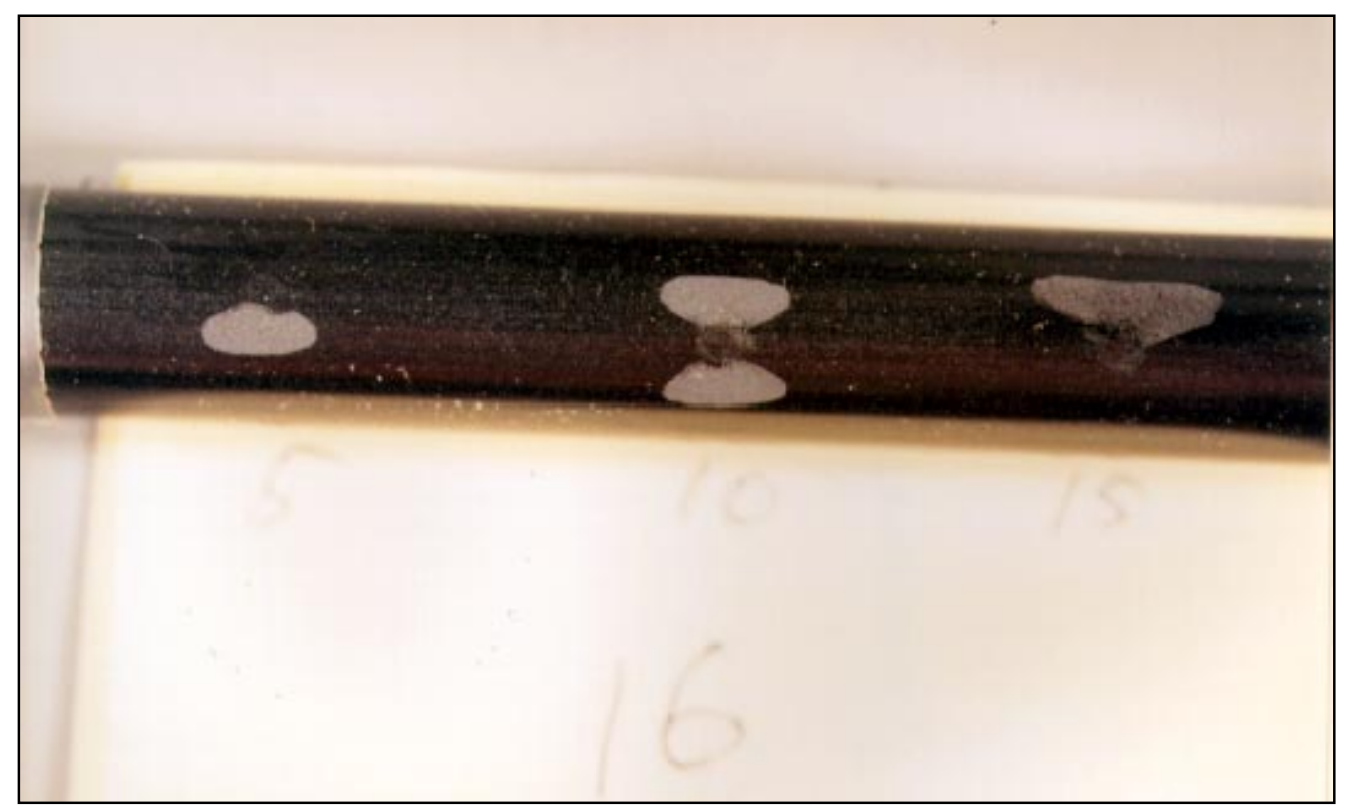

Figure 26. Impact specimen \#16 showing results of impact energies of 5,10 , and 15 in.-lb, starting from the left.

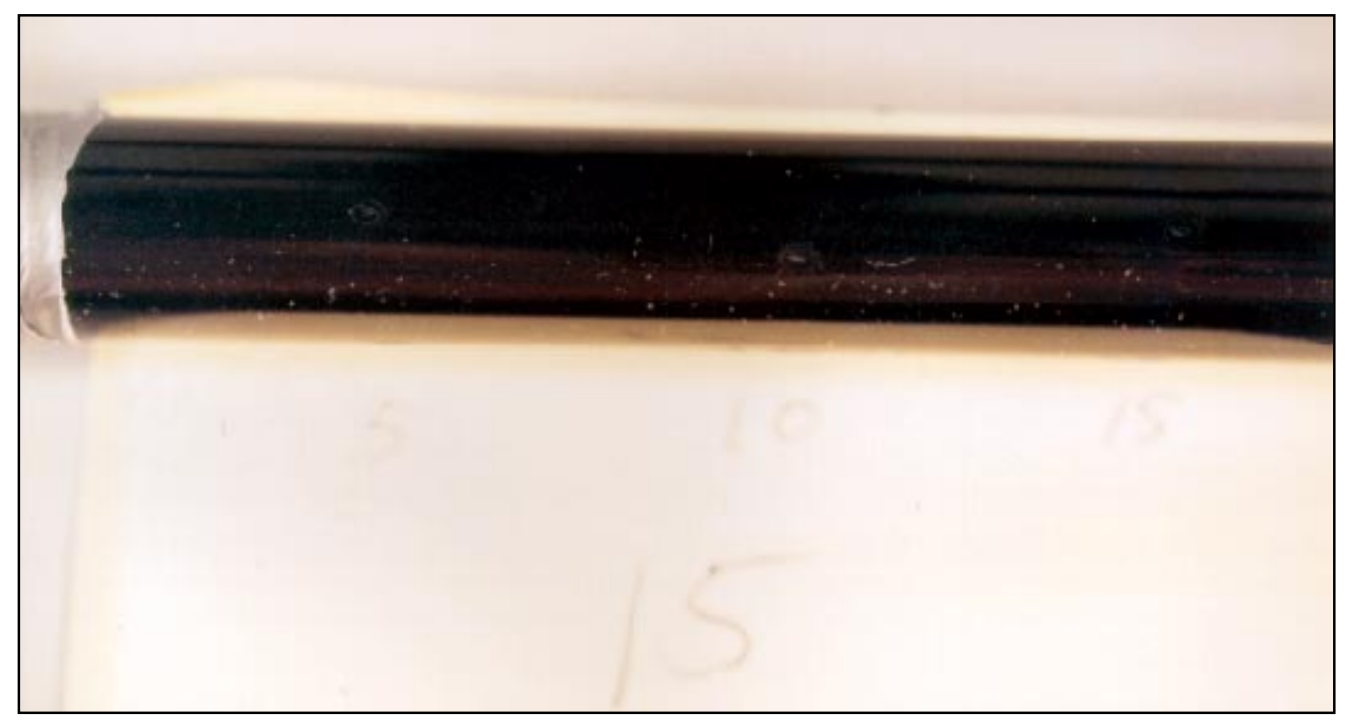

Figure 27. Impact specimen \#15 showing results of impact energies of 5,10 , and 15 in.-lb, starting from the left. 


\section{Conclusions and Recommendations}

\section{Conclusions}

The use of ceramic coated piston rods is controlled by CEGS 15010, "Hydraulic Power Systems for Civil Works Structures." In sections 2.1.3.4, 2.1.4, and 2.1.5.1, the specification calls for:

- the ceramic coating to be 200 micrometers (0.008 in.) minimum thickness

- a surface finish of 0.30 to 0.35 micrometer (12 to 14 micro-in.) rms

- a surface hardness of $67 \mathrm{R}_{c}$ minimum, impact resistance of 7 to $15 \mathrm{~N}-\mathrm{m}$ (5 - $17 \mathrm{lb}-\mathrm{ft})$

- modulus of elasticity of 360 to $450 \mathrm{gPa}\left(52 \times 10^{6}\right.$ to $\left.60 \times 10^{6} \mathrm{psi}\right)$

- linear expansion coefficient of $7.2 \times 10^{-6} /{ }^{\circ} \mathrm{C}\left(4.0 \times 10^{-6} /{ }^{\circ} \mathrm{F}\right)$

- capability of withstanding a fracture force of $280 \mathrm{mPa}$ (41 ksi) minimum.

No mention of surface preparation is made in the document. Surface preparation is a critical step in the application of a good ceramic coating on any substrate. The criteria in the guide specification for impact resistance is unclear as to how it should be applied. If the coatings have to absorb this high an energy level without any damage, it seems unlikely that any ceramic material can do it. The same comments apply to the fracture force requirement. How is it measured? Is the fracture force to be applied while the ceramic material is in a thin layer on the substrate or to a solid block of the ceramic? Also, how is the force to be applied, statically or dynamically, tension, compression, or shear?

The coating application method directly affects the coating structure and consequently, the coating's properties. Preparation of the substrate is imperative for good bonding of the coating system. Surface profiles of Ra 350 micro-in. to Ra 500 micro-in. have produced good surfaces for bonding. The bond coat should be applied within 4 hours of surface preparation. For bond coats, the metal alloys must be pre-alloyed. Composite materials such as agglomerated nickel- 
aluminum are specifically not recommended. Porosity should be low as measured by optical methods on polished specimens. Recommended bond coat materials include nickel-chrome alloy, nickel-aluminum alloy and molybdenum. Recommended topcoat materials include alumina- $13 \%$ titania, alumina- $40 \%$ titania, chromia, and chromia-5\% silica-3\% titania. The function of the sealer is to block passage through the inherent porosity of thermally sprayed coatings to the substrate. Recommended sealers include phenolics, low viscosity epoxies (i.e., Lock-Tite 190), urethanes, silicones, and polyamides. The coatings should be finished by grinding.

Specimens $1,5,6,12,13,15$, and 19 are free from any corrosion of the substrate from the salt spray test. Specimens 7 and 16 showed the best results with no cracks appearing on the tension side during the three-point bend test. Specimens $1,3,7,18$, and 21 had minimal cracking as a result of the 5 in.-lb impact. Specimens 4, 12, 13, 15, and 21 had no spalling and only some cracking at the 15 in.-lb energy level. None of the samples met the impact criteria of 5 to $17 \mathrm{ft}-\mathrm{lb}$ impact loading without damage. All of the specimens had some type of damage from the impact of the ball on its surface at all energy levels. The brittleness of the ceramic coatings does not allow the material to absorb much energy before it sustains some kind of damage from impact. Overall, specimens 15 and 21 did the best in the varying impact loading. Specimen 17 had the lowest hardness number at 81.06, which is equivalent to a Rockwell " $\mathrm{C}$ " of approximately 41.5 . Specimen 8 had the highest hardness number at 95.06 , which is equivalent to a Rockwell " $\mathrm{C}$ " of 74. The average hardness for the specimens with the alumina top coating were all within three hardness numbers of each other except sample 17, which had a molybdenum bond coat. The average hardness for specimens with the pure chromia top coat were all within two hardness numbers of each other. The Rexroth samples had a hardness number within the range for the alumina coated samples. Only specimens $7,8,9,10,11$, and 16 had hardness numbers over the minimum Corps requirement. These specimens had the pure chromia topcoat with either no bond coat, a plasma sprayed coating of 400 series stainless steel, or a plasma sprayed nickel-chrome coating.

Specimen 15 was the best overall performer in this series of tests. This specimen had 316 Stainless Steel bond coat plasma sprayed and an alumina - 40\% titania topcoat with no sealer. The stainless steel bond coat protected the steel substrate during the corrosion tests. Even with bending and impact incidents the bond coat will continue to protect the substrate from corrosion. This system also out-performed the other coating systems in the impact and bend tests. 


\section{Recommendations}

It is recommended that:

- the surface preparation for steel substrates of 350 to 500 micro inches be included as part of the Corps CEGS

- the impact resistance values be modified downward to 5 to $15 \mathrm{in}$.-lb without spalling of the ceramic coating

- the fracture force requirement either be eliminated or be better defined in the guide specification. 


\section{References}

American Society for Testing and Materials (ASTM) B-117-90 “Standard Test Method of Salt Spray (Fog) Testing."

ASTM D-2794-93 “Standard Testing Method for Resistance of Organic Coatings to the Effects of Rapid Deformation (I mpact)."

ASTM E-18-93 "Standard Test Methods for Rockwell Hardness and Rockwell Superficial Hardness of Metallic Materials."

ASTM E-290-92 "Standard Test Method for Semi-Guided Bend Test for Ductility of Metallic Materials."

Corps of Engineers Guide Specification 15010, "Hydraulic Power Systems for Civil Works Structures." 